\title{
Phenotypic Characterization and Comparison of Cystic Fibrosis Rat Models Generated Using CRISPR/Cas9 Gene Editing
}

\author{
Alexandra McCarron, ${ }^{* \dagger \ddagger}$ Patricia Cmielewski, ${ }^{* \dagger \ddagger}$ Nicole Reyne, ${ }^{* \dagger \ddagger}$ Chantelle McIntyre, ${ }^{\dagger \S}$ John Finnie, $^{\dagger \uparrow}$ Fiona Craig, ${ }^{\dagger}$ \\ Nathan Rout-Pitt, ${ }^{\star \dagger \ddagger}$ Juliette Delhove, ${ }^{* \dagger}$ John E. Schjenken, ${ }^{\dagger \ddagger}$ Hon Y. Chan, ${ }^{\dagger \ddagger}$ Bernadette Boog, ${ }^{* \dagger \ddagger}$ Emma Knight, \\ Rodney C. Gilmore, "Wanda K. O'Neal, "Richard C. Boucher, "David Parsons, ${ }^{* \dagger \ddagger}$ and Martin Donnelley*
}

\begin{abstract}
From the Department of Respiratory and Sleep Medicine,*Women's and Children's Hospital, North Adelaide, South Australia, Australia; the Adelaide Medical School ${ }^{\dagger}$ and the Robinson Research Institute, ${ }^{\ddagger}$ University of Adelaide, Adelaide, South Australia, Australia; Genetics and Molecular Pathology, ${ }^{\S}$ SA Pathology at Women's and Children's Hospital, North Adelaide, South Australia, Australia; the Division of Anatomical Pathology, ${ }^{\top}$ SA Pathology, Adelaide, South Australia, Australia; and the Marsico Lung Institute/Cystic Fibrosis Research Center," University of North Carolina at Chapel Hill, Chapel Hill, North Carolina
\end{abstract}

\author{
Accepted for publication \\ January 21, 2020. \\ Address correspondence to \\ Alexandra McCarron, B.Sc. and \\ B.Hlth.Sc. (Hons.), or Martin \\ Donnelley, Ph.D., 72 King \\ William Rd., North Adelaide, \\ South Australia 5006, Australia. \\ E-mail: alexandra.mccarron@ \\ adelaide.edu.au or martin. \\ donnelley@ adelaide.edu.au.
}

\begin{abstract}
Animal models of cystic fibrosis (CF) are essential for investigating disease mechanisms and trialing potential therapeutics. This study generated two CF rat models using clustered regularly interspaced short palindromic repeats/clustered regularly interspaced short palindromic repeats-associated protein 9 gene editing. One rat model carries the common human Phe508del ( $\Delta F 508)$ CF transmembrane conductance regulator (CFTR) mutation, whereas the second is a CFTR knockout model. Phenotype was characterized using a range of functional and histologic assessments, including nasal potential difference to measure electrophysiological function in the upper airways, RNAscope in situ hybridization and quantitative PCR to assess CFTR mRNA expression in the lungs, immunohistochemistry to localize CFTR protein in the airways, and histopathologic assessments in a range of tissues. Both rat models revealed a range of CF manifestations, including reduced survival, intestinal obstruction, bioelectric defects in the nasal epithelium, histopathologic changes in the trachea, large intestine, and pancreas, and abnormalities in the development of the male reproductive tract. The CF rat models presented herein will prove useful for longitudinal assessments of pathophysiology and therapeutics. (Am J Pathol 2020, 190: 977-993; https://doi.org/10.1016/j.ajpath.2020.01.009)
\end{abstract}

Cystic fibrosis (CF) is a chronic and life-shortening autosomal recessive disorder caused by mutations in the gene encoding the cystic fibrosis transmembrane conductance regulator $(C F T R)$ anion channel. In epithelial cells, the CFTR channel is responsible for chloride and bicarbonate transport, as well as the regulation of epithelial sodium channels. ${ }^{1}$ CFTR dysfunction leads to disease manifestations in a diverse range of organs, including the lungs, gastrointestinal tract, liver, pancreas, and reproductive tract. ${ }^{2}$ Pulmonary disease is currently the greatest contributor to morbidity and mortality among CF patients, and is therefore the primary focus for therapy development.

Animal models of CF that can accurately recapitulate the human disease are critical for elucidating the mechanisms that underlie disease pathogenesis and for trials of potential therapeutics. In the United States, CF models now include several mouse models, ${ }^{3,4}$ pigs, ${ }^{5}$ ferrets, ${ }^{6}$ and rats. ${ }^{7}$ Sheep ${ }^{8}$ and rabbit ${ }^{9}$ models have also recently been reported.

\footnotetext{
Supported by Cystic Fibrosis South Australia for seed funding to establish the cystic fibrosis rat colony and in part by the Fay Fuller Foundation, the National Health and Medical Research Council GNT1160011, the Cystic Fibrosis Foundation PARSON18GO for the characterization studies, a MS McLeod PhD scholarship (A.M.). The Australian Phenomics Network is supported by the Australian Government through the National Collaborative Research Infrastructure Strategy Program.

A.M. and P.C. contributed equally to this work.

D.P. and M.D. contributed equally as senior authors.

Disclosures: None declared.
} 
Characterization of these animal models reveals varying presence and severity of $\mathrm{CF}$ phenotypes, with no single animal model recapitulating all features of human CF disease. ${ }^{10-12}$ Nonetheless, these models are proving useful for investigating $\mathrm{CF}$ pathophysiology ${ }^{13,14}$ and evaluating therapeutics, such as airway gene therapies, ${ }^{15-20}$ CFTR modulators, ${ }^{21}$ and novel pharmacotherapeutics. ${ }^{22}$

Because of quarantine laws and licensing restrictions, US-generated CF animal models can be difficult to establish in Australia. As such, this study sought to generate an alternate $\mathrm{CF}$ animal model for Australasian researchers. Unlike nonlaboratory animals, rodents do not require specialized housing facilities, have relatively low husbandry costs, and are easy to breed. Rat airways are attractive candidates for CF modeling as they have similar cellular architecture to humans, including an abundance of submucosal glands throughout the trachea and bronchi, which are known to be implicated in the development of CF airway disease. ${ }^{23,24}$ Furthermore, a previously developed CFTR knockout (KO) rat has already shown encouraging results, with the rats developing a range of $\mathrm{CF}$ manifestations, including aspects of lung disease. ${ }^{7,14}$ USgenerated $\mathrm{KO}$ rats also appear to exhibit milder disease phenotypes when compared with pig and ferret models, thus enabling longitudinal assessment of therapeutics.

Using clustered regularly interspaced short palindromic repeats (CRISPR)/CRISPR-associated protein 9 (Cas9) gene editing, this study generated the first known mutationspecific CF rat model bearing the Phe508del CFTR mutation (alias $\Delta \mathrm{F} 508$ ). Phe508del is a class II CFTR mutation, and is the most common, with approximately $90 \%$ of patients carrying at least one copy. ${ }^{25}$ The Phe508del mutation results in an absence of phenylalanine at position 508, which leads to protein misfolding, retention of the mutant CFTR in the endoplasmic reticulum, and its subsequent degradation by the cellular quality control mechanisms. Although a small amount of CFTR protein may be trafficked to the plasma membrane, the channel gating is also defective and the protein has a short half-life. ${ }^{26,27}$ In the process of generating a founder animal carrying the Phe508del mutation, an animal with an 8-bp deletion in exon 11 of CFTR was generated as a result of nonhomologous end joining DNA repair. This mutation results in the introduction of a premature termination codon at position 510 , and as such, the animal was used as a founder to breed KO rats.

This article describes the generation, phenotype characterization, and a comparative assessment of the Phe508del and $\mathrm{KO}$ rat strains.

\section{Materials and Methods}

\section{Generation of Founder Animals}

\section{CRISPR/Cas9 Gene Editing and Microinjection}

Design of the CRISPR/Cas9 strategy, microinjections into rat embryos, and identification of founder animals were performed by the Australian Phenomics Network at Monash University (http://www.australianphenomics.org. $a u$, last accessed October 28, 2019). Generation of the founders was conducted under approval from the Monash University animal ethics committee. The Phe508del model was generated using CRISPR/Cas9 and a homology-directed repair DNA template containing a TTT deletion corresponding to position 508 in the rat CFTR sequence (NM_031506.1). The guide RNA was generated using the HiScribe T7 Quick High Yield RNA Synthesis Kit (New England Biolabs, Ipswich, MA). Table 1 contains the sequences for the homology-directed repair oligonucleotide and guide RNA used. Microinjection was performed into Sprague-Dawley one-cell embryos (C076 line) using $30 \mathrm{ng} / \mathrm{mL}$ of Cas 9 mRNA, 15 $\mathrm{ng} / \mathrm{mL}$ of guide RNA, and $30 \mathrm{ng} / \mathrm{mL}$ of homology-directed repair template. Embryos were subsequently transferred to pseudopregnant females, resulting in generation of the founder animals.

\section{Identification of Founder Animals}

DNA extraction was performed on tail biopsies using the Qiagen (Hilden, Germany) DNeasy blood and tissue kit, as per the manufacturer's instructions. PCR was performed using forward $5^{\prime}$-CTGGAAGCGTCAGAGGGAAT- $3^{\prime}$ and reverse $5^{\prime}$-ACACAAGTAGCTAACACGGATGT-3 ${ }^{\prime}$ primers flanking the mutation target site. The subsequent PCR product was purified and cloned into pGEM-T Easy vectors. The clone DNA was isolated and sequenced by the Micromon Sequencing Facility (Monash University) to identify mutants. The selected founders were mated with wild-type Sprague-Dawley rats (sourced from the South Australian Health and Medical Research Institute) to produce heterozygous animals. Heterozygous siblings were subsequently paired to generate homozygous Phe508del and $\mathrm{KO}$ animals.

\section{Characterization of the Models}

\section{Animal Husbandry}

Animal studies were conducted under approval from the University of Adelaide Animal Ethics Committee. All animals were maintained in conventional rat cages with a 12-hour light/ dark cycle. Food and water were provided ad libitum, with all rats receiving a 50:50 mix of normal and high-fat (10\%) rodent chow. Once identified, wild-type and heterozygous animals were provided with normal drinking water, whereas $\mathrm{CF}$ animals received 4.5\% ColonLYTELY (Dendy Pharmaceuticals, Moorabbin, VIC, Australia) in the water to reduce the incidence of fatal gastrointestinal obstructions. CF rats experience incisor overgrowth; therefore, their teeth were trimmed as required using a small rotary-saw (Dremel 4300-5/50) while anesthetized with inhaled isoflurane (2\%). Moistened rodent chow was provided daily to animals that had ongoing tooth issues. $\mathrm{KO}$ rat production was maintained by breeding heterozygous 
Table 1 CRISPR/Cas9 gRNA and HDR Template Sequences

\begin{tabular}{ll}
\hline Template & Sequence \\
\hline gRNA & 5'-ATCAAAGAAAATATCATCTT (TGG) - 3' \\
HDR & 5'-GTTTCATTCTCCTCTCAAATT- \\
oligonucleotide & TCTTGGATTATGCCGGGTACT- \\
& ATCAAAGAAAATATCATCGGT- \\
& GTTTCCTATGATGAGTACAGA- \\
& TATAAGAGTGTTGTCAAAGCT- \\
& TGCCAACTACAGGAG-3' \\
\hline
\end{tabular}

PAM shown in parentheses.

Cas9, CRISPR-associated protein 9; CRISPR, clustered regularly interspaced short palindromic repeats; gRNA, guide RNA; HDR, homologydirected repair; PAM, protospacer adjacent motif.

pairs, whereas Phe508del animals were maintained using homozygous Phe508del females and heterozygous males.

\section{Genotyping}

Genomic DNA was extracted from ear notch tissue using the Wizard SV Genomic DNA Purification System (Promega), as per the manufacturer's instructions. Genomic DNA was amplified using a T100 thermal cycler (Bio-Rad, Hercules, CA) with Extract-N-Amp PCR reaction mix (Sigma, St. Louis, MO) and $0.4 \mu \mathrm{mol} / \mathrm{L}$ of each primer (as stated above for genotype identification). PCR conditions were an initial denaturation at $94^{\circ} \mathrm{C}$ for 2 minutes, followed by 35 cycles of $94^{\circ} \mathrm{C}$ for 30 seconds, $54^{\circ} \mathrm{C}$ for 30 seconds, and $72^{\circ} \mathrm{C}$ for 30 seconds, with a final extension of $72^{\circ} \mathrm{C}$ for 5 minutes. This PCR results in amplification of a 189-bp DNA fragment for the wild-type CFTR allele, a 186-bp (3 bp deleted) DNA fragment for the Phe508del allele, and a 181-bp ( 8 bp deleted) fragment for the knockout allele. PCR products were purified (PureLink Quick PCR Purification Kit; Invitrogen, Carlsbad, CA) and directly sequenced using the Big Dye Terminator Cycle sequencing version 3.1 (Applied Biosytems, Foster City, CA) and run on a 3730/ 3730xl DNA Analyzer with 50-cm capillaries, running POP-7 polymer (Applied Biosystems). Sequence analysis was performed using SnapGene (GSL Biotech LLC, San Diego, CA).

Quantitative Real-Time PCR for CFTR mRNA Quantification Frozen lung samples stored at $-80^{\circ} \mathrm{C}$ in RNAlater (Sigma-Aldrich, St. Louis, MO) were used for CFTR mRNA quantification. Total RNA was isolated from lung samples using a Qiagen RNeasy PowerLyzer tissue and cell kit, and cDNA was subsequently synthesized using a Qiagen QuantiTect Reverse Transcription Kit. For measuring total CFTR mRNA, primers for rat CFTR (forward, 5'-AAGCTGAAAGCAGGTGGGAT-3'; and reverse, $5^{\prime}$-TGCTCCGACCACAATGAACA- $3^{\prime}$ ) and housekeeping gene cyclophilin A (forward, 5'-GGTTGGATGGCAAGCATGTG- $3^{\prime}$; and reverse, $5^{\prime}$-TGCTGGTCTTGCCATTCCTG$3^{\prime}$ ) were used in separate reactions. Cyclophilin A was selected as the housekeeping gene because of its stable expression in bronchial epithelial cells. ${ }^{28}$ CFTR mRNA abundance was quantified by quantitative PCR using SYBR Green (Bio-Rad CFX Connect Real-Time PCR system). The thermocycler conditions were as follows: $50^{\circ} \mathrm{C}$ for 2 minutes, $95^{\circ} \mathrm{C}$ for 10 minutes, followed by 40 cycles of $95^{\circ} \mathrm{C}$ for 15 seconds and $58^{\circ} \mathrm{C}$ for 60 seconds. CFTR mRNA expression was normalized to cyclophilin A mRNA expression.

\section{Histology}

Histologic analyses were performed on tissues from 1-month-old animals, except for the testes, where tissues from sexually mature males (aged 8 to 12 weeks) were used. Lungs were cannulated, and the left and top right lung lobes were inflation fixed with $10 \%$ neutral-buffered formalin. Heads were collected (for examination of the nasal passages), immersion fixed in $10 \%$ neutral-buffered formalin, and transferred to 25\% EDTA for 7 to 14 days $\left(\right.$ at $37^{\circ} \mathrm{C}$ ) to decalcify the tissue. The nasal cavity was then cut into four sections at specific palatal sites, as previously described. ${ }^{29}$ Liver, pancreas, and gastrointestinal tract tissues were immersion fixed in $10 \%$ neutral-buffered formalin for 24 to 48 hours and stored in $70 \%$ ethanol until processing. Testes were preserved in Davidson's fixative, followed by daily changes with $70 \%$ ethanol for 3 days. All fixed tissues were paraffin embedded, divided into sections ( $6 \mu \mathrm{m}$ thick), and stained with hematoxylin and eosin or Alcian blue periodic acid-Schiff for blinded evaluation by a veterinary pathologist (J.F.). Wild-type age-matched rats were used as controls, and a minimum of eight animals (four females and four males) were used for analysis of each organ. Histologic images were examined and captured on a Nikon Eclipse E400 microscope (Tokyo, Japan) with DS-Fi2-U3 camera and NIS-elements D software version 4.20.02 (Nikon).

Morphometric Analysis of Tracheal Tissue

Alcian blue periodic acid-Schiff stained longitudinal tracheal sections were imaged at either $\times 100$ or $\times 200$ magnification. Using the NIS-elements D image analysis software, the submucosal gland mucus components were identified and traced, and their areas were quantified. The length of the trachea section was also measured in millimeters to normalize submucosal gland mucus area.

Table 2 Genotype Distribution Observed for the Phe508del and Knockout Rat Strains

\begin{tabular}{lcll}
\hline Genotype & Wild-type & Heterozygous & CF \\
\hline Phe508del $^{*}$ & 0 & 47.2 & 52.8 \\
Knockout $^{\dagger}$ & 26.7 & 51.9 & 21.4 \\
\hline
\end{tabular}

Data are given as percentage.

*Heterozygous male to homozygous female breeding.

${ }^{\dagger}$ Heterozygous male to heterozygous female breeding.

CF, cystic fibrosis. 


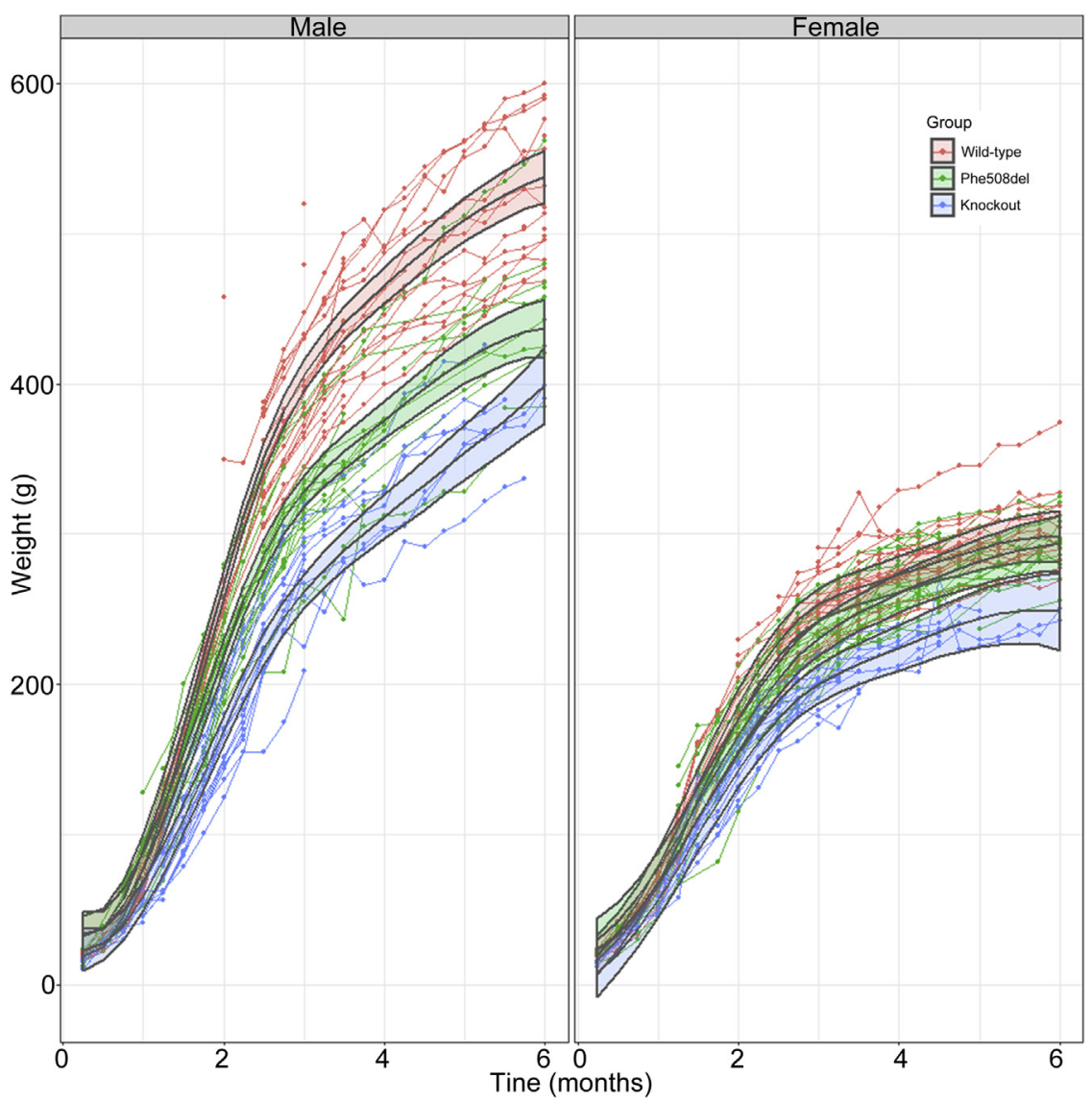

Figure 1 Body weight for male and female wild-type, Phe508del, and knockout rats from day 1 postnatal to 6 months of age. Data presented as the estimated mean weight at each time point from the linear mixed model and 95\% CI. $n=23$ to 36 animals per group.
RNA in Situ Hybridization (RNAscope)

Inflation-fixed, paraffin-embedded lung tissue sections from 1-month-old rats were used for analyses. In situ RNA detection was performed using the RNAscope 2.5 Red HD Detection kit from Advanced Cell Diagnostics Inc. (Hayward, CA). The probes used were rat CFTR (cystic fibrosis transmembrane conductance regulator from Rattus norvegicus) $\mathrm{Rn}-\mathrm{Cftr}-\mathrm{No}-\mathrm{XHs}$, positive control rat probe (peptidylprolyl isomerase $\mathrm{B}$ ), and negative control probe DapB (4-hydroxy-tetrahydrodipicolinate reductase from Bacillus subtilis). Slides were hybridized with the probes in a HybEZ oven (Advanced Cell Diagnostics Inc.), at $40^{\circ} \mathrm{C}$ for 2 hours. After hybridization, slides were subjected to signal amplification, according to the manufacturer's instructions. Hybridization signals were detected using a mixture of solutions A and B (1:60) in RNAscope 2.5 HD Red Assay. After counterstaining with $50 \%$ hematoxylin, slides were dried in a $60^{\circ} \mathrm{C}$ dry oven for 30 minutes and mounted with VectaMount (Advanced Cell Diagnostics Inc.). The integrated probe design with signal amplification and detection was used to

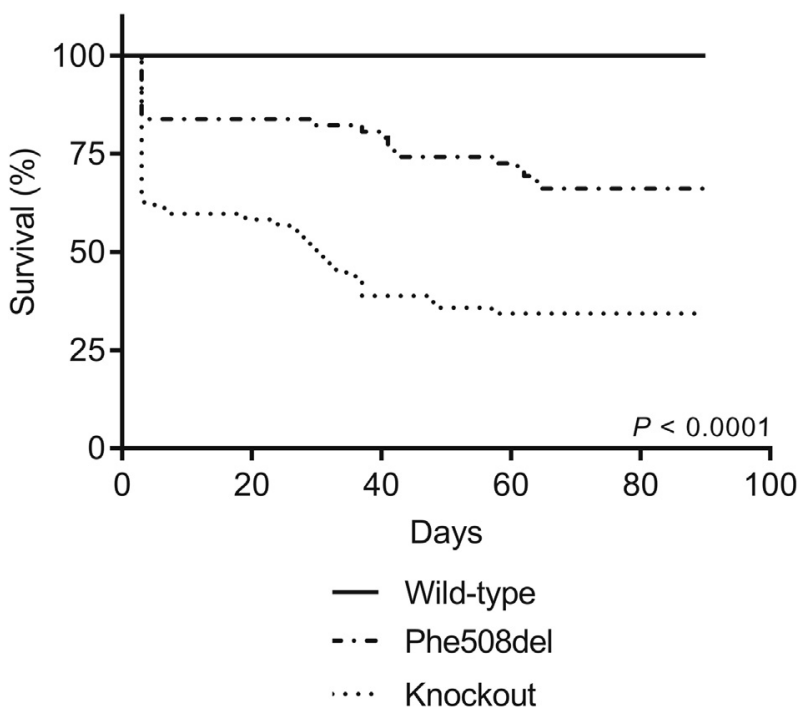

Figure 2 Survival curve for Phe508del and knockout rats from postnatal day 1 to 90 . All animals included in the survival analyses were reared on high-fat rodent chow and ColonLYTELY in the drinking water. Individuals with unknown genotypes were not included. $n=38$ to 67 animals per group. $P<0.0001$ for all groups (pairwise comparisons). 


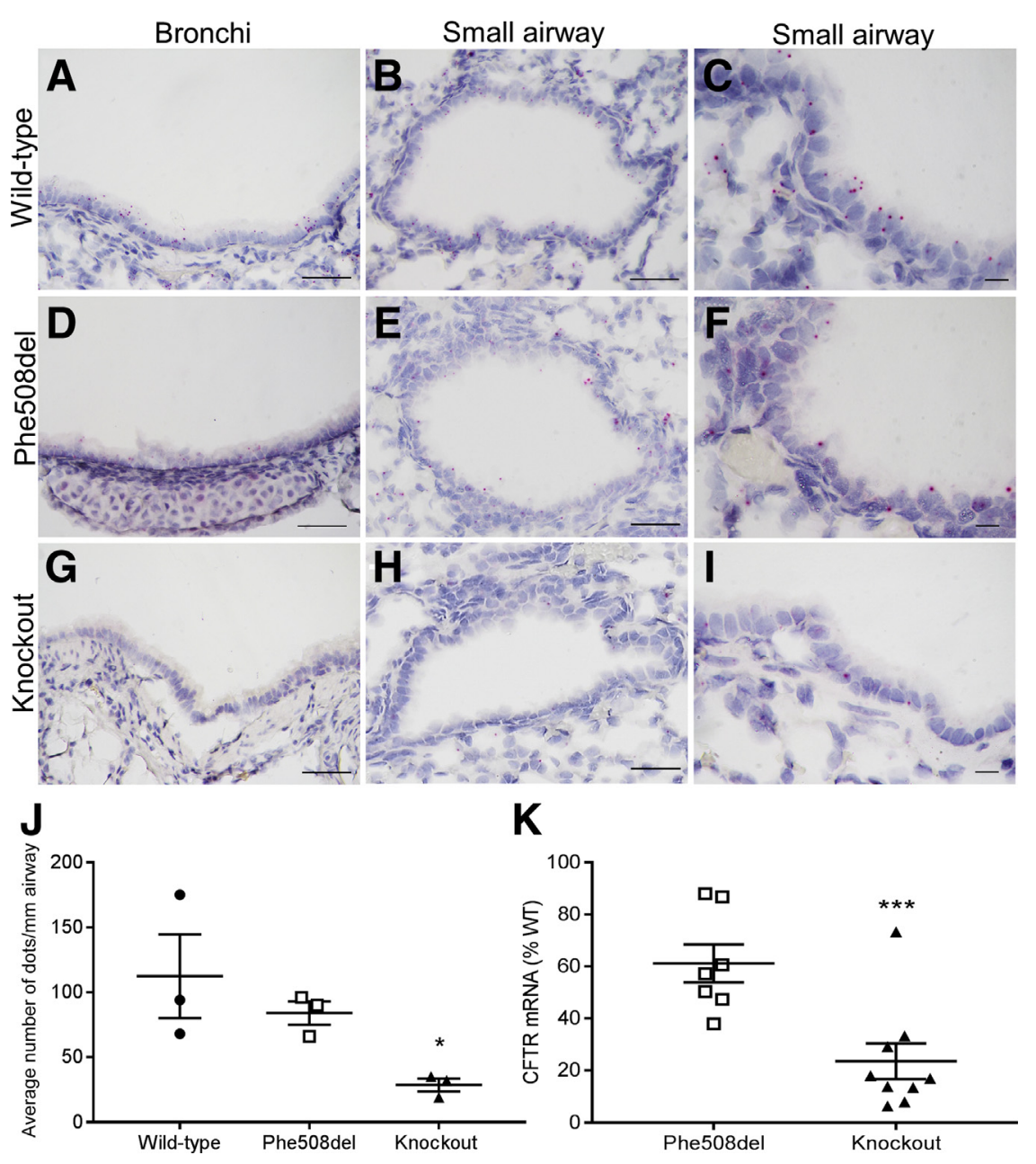

Figure 3 Cystic fibrosis transmembrane conductance regulator (CFTR) mRNA expression in the lungs of Phe508del and knockout (KO) rats. A-K: Representative images of RNAscope in situ hybridization for the detection of CFTR mRNA in the lungs. A-C: Bronchi and small airways of wildtype (WT) animals show robust CFTR mRNA expression, indicated by the magenta dots. $\mathbf{D}-\mathbf{F}$ : Phe508del airways show similar mRNA expression levels and localization to wild-type rats. G-I: KO rats show a significant reduction in CFTR mRNA levels in both large and small airways. J: Quantification of airway epithelial CFTR transcripts from RNAscope in situ hybridization. Graph presents average counts of five airways per animal. K: CFTR mRNA levels evaluated using quantitative PCR. CFTR expression is displayed as a percentage of wild-type CFTR expression. Data are expressed as means \pm SEM ( $\mathbf{J}$ and $\mathbf{K}$ ). $n=3$ animals per group $(\mathrm{A}-\mathrm{J}) ; n=7$ to 9 animals per group (K). ${ }^{*} P<0.05,{ }^{* * *} P<0.001$ versus WT (one-way analysis of variance). Scale bars: $50 \mu \mathrm{m}$ (A-I, left and middle columns); $10 \mu \mathrm{m}$ (A-I, right column).

achieve single-molecule detection of CFTR mRNA (labeled magenta).

\section{RNAscope CFTR Transcript Quantification}

Hybridized lung sections were imaged at $\times 400$ magnification. Quantification of CFTR transcripts was performed using the NIS-elements D image analysis software. Five airways were randomly selected per animal, each airway was measured in length (millimeters), and the magenta-labeled dots were manually counted within the airway epithelial layer.

\section{Immunohistochemistry}

Lung samples from rats and a University of North Carolina CFTR-knockout mouse (used as a CFTR-negative control) were fixed in $10 \%$ neutral-buffered formalin, paraffin embedded, divided into sections ( $5 \mu \mathrm{m}$ thick), and deparaffinized using standard histologic procedures. Antigen retrieval was performed using $10 \mathrm{mmol} / \mathrm{L}$ sodium citrate ( $\mathrm{pH}$ 6.0) for 20 minutes, followed by permeabilization in Tris-buffered saline/Triton X-100 (0.3\%) for 10 minutes. Sections were blocked for 1 hour at room temperature in a solution of serum-free protein block (Dako, Santa Clara, CA), $10 \%$ normal goat serum, and $0.1 \%$ Tween-20. Primary antibodies rabbit $\alpha$-CFTR (1:300 dilution; Abcam, Cambridge, UK; ab181782) and mouse $\alpha$-lysosomal-associated membrane protein 1 (1:200 dilution; Santa-Cruz Biotechnology, Dallas, TX; sc-17768) were resuspended in blocking buffer and incubated with samples overnight at $4^{\circ} \mathrm{C}$. A secondary antibody-only control was incubated in blocking buffer without primary antibody overnight at $4^{\circ} \mathrm{C}$. Slides were washed three times in Tris-buffered saline/Tween-20 $(0.1 \%)$ for 5 minutes, followed by incubation with $\alpha$-rabbit Alexa Fluor 488 (Invitrogen; ab150073) and $\alpha$-mouse Alexa Fluor 568 (Invitrogen; A11004) in blocking buffer at room temperature for 1 hour. Samples were washed three times in Tris-buffered saline/Tween-20 (0.1\%), followed by counterstaining and mounting with ProLong Diamond Antifade Mountant with DAPI (Molecular Probes, Eugene, OR). Images were generated using a Nikon Ts 2 or Olympus FV3000 confocal microscope (Toyko, Japan). The rabbit $\alpha$-CFTR antibody used had an epitope specificity to amino acids 100 to 200 of the CFTR protein.

\section{Nasal Potential Difference Measures}

Rats were anesthetized using a mixture of medetomidine $(0.4 \mathrm{mg} / \mathrm{kg})$ and ketamine $(60 \mathrm{mg} / \mathrm{kg})$ by i.p. injection and 


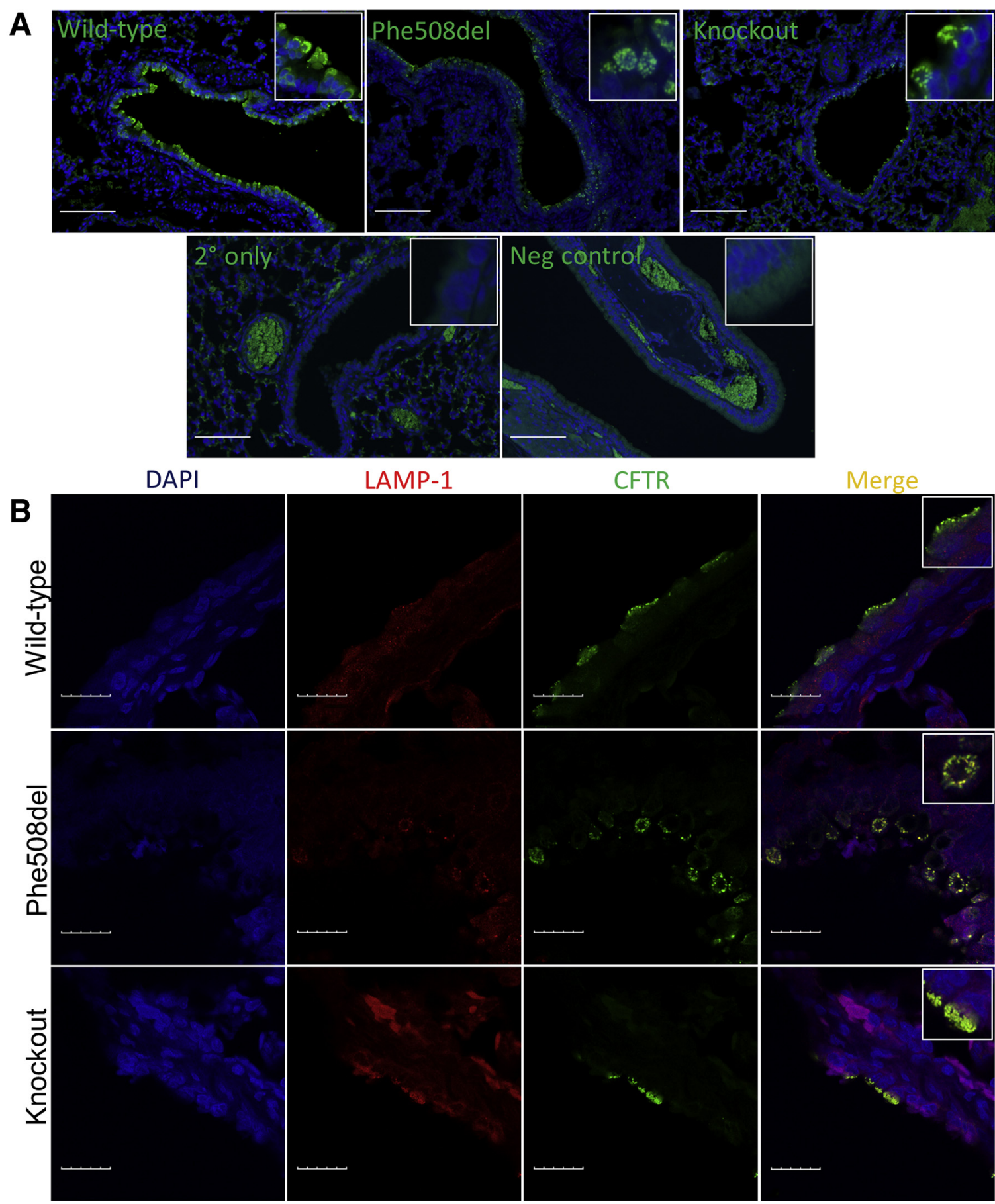

Figure 4 Immunohistochemical localization of cystic fibrosis transmembrane conductance regulator (CFTR) in Phe508del and knockout (K0) rats. A: Bronchioles exhibit varying levels of CFTR protein expression between the genotypes. Lung tissue from University of North Carolina CFTR-knockout mice was used as a negative control for CFTR. Insets: Enlarged images of CTFR stained airway epithelium. B: Colocalization of CFTR with the lysosomal marker, lysosomalassociated membrane protein 1 (LAMP-1), demonstrates degradation of misfolded protein and differential localization of CFTR in Phe508del and K0 rats when compared with wild-type. Insets: Enlarged images of colocalized staining. $n=3$ animals per genotype (A and B). Scale bars: $100 \mu \mathrm{m}$ (A); $20 \mu \mathrm{m}$ (B). Neg, negative.

were nonsurgically intubated with a $16 \mathrm{G}$ i.v. cannula (Terumo, Tokyo, Japan) to permit normal breathing during nasal perfusions. Rats were suspended by their incisors on a frame that held them upright, and the exploring electrode was inserted approximately $7 \mathrm{~mm}$ into the nasal cavity, with a reference electrode inserted subcutaneously into the abdomen. Nasal cavities were perfused at a rate of 10 to $25 \mu \mathrm{L} /$ minute with the following solutions: i) normal KrebsRinger buffer (basal Krebs-Ringer buffer), ii) Krebs-Ringer buffer containing $100 \mu \mathrm{mol} / \mathrm{L}$ amiloride, iii) low-chloride 

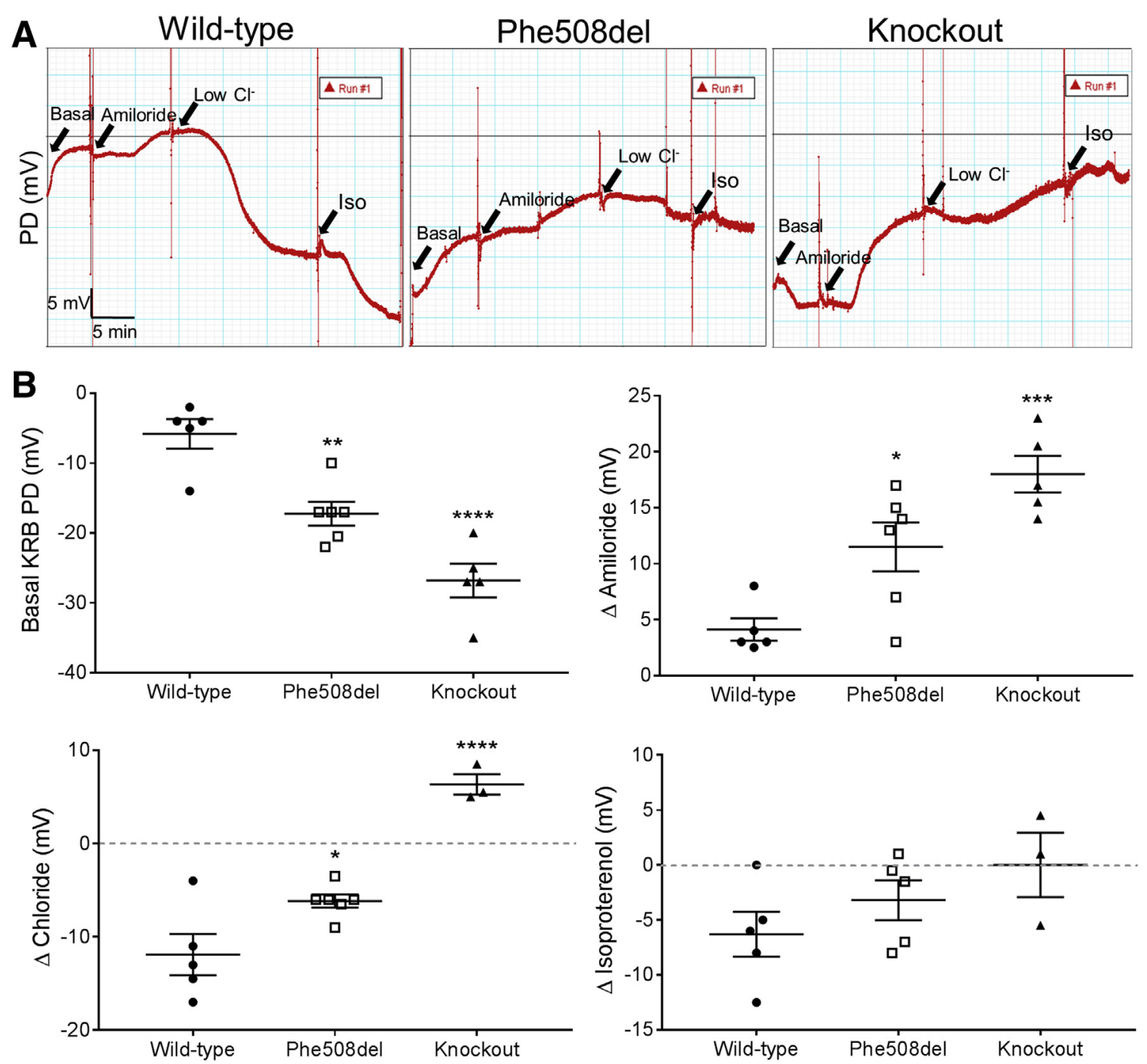

Figure 5 Nasal potential difference (NPD) measurements. A: Representative NPD traces from wild-type (WT), Phe508del, and knockout rats. B: Summary data for NPD measurements for baseline PD response to basal Krebs-Ringer buffer (KRB), $\triangle P D$ amiloride, $\triangle P D$ chloride, and $\triangle P D$ isoproterenol (Iso). Dashed lines indicate $0 \mathrm{mV}$. Data are expressed as means \pm SEM (B). $n=3$ to 6 animals per genotype (B). ${ }^{*} P<0.05,{ }^{*} P<0.01,{ }^{* *} P<0.001$, and $* * * * P 0.0001$ versus WT (one-way analysis of variance).

Krebs-Ringer buffer with $100 \mu \mathrm{mol} / \mathrm{L}$ amiloride, and iv) low-chloride Krebs-Ringer buffer containing $100 \mu \mathrm{mol} / \mathrm{L}$ amiloride plus $100 \mu \mathrm{mol} / \mathrm{L}$ isoproterenol. Each solution was perfused for at least 5 to 10 minutes until a plateau of 1 to 2 minutes was maintained. All nasal potential difference tracings were interpreted by an experienced assessor blinded to the animal genotype (D.P.).

\section{Blood Counts and Serum Chemistry}

Blood was collected from adult rats by terminal cardiac puncture and stored in lithium heparin tubes. Whole blood was processed for complete blood cell counts and serum chemistry by Gribbles Veterinary Pathology (Clayton, VIC, Australia). Serum samples were analyzed on a Siemens Advia 1800 (Tarrytown, NY). The results were compared with a reference range for wild-type Sprague-Dawley rats. ${ }^{30}$
Bronchoalveolar Lavage Fluid Cell Differentials

Tracheas were cannulated and lungs were lavaged with 3.0 $\mathrm{mL}$ phosphate-buffered saline. Lavage was centrifuged onto slides (Cytospin), and cells were fixed and stained using Giemsa. A minimum of 300 cells per animal were counted.

\section{Statistical Analysis}

Statistical analyses were performed using either GraphPad Prism version 7 (GraphPad Software, Inc., San Diego, CA) or $\mathrm{R}$ version 3.6.1. ${ }^{31}$ To investigate the differences in body weight trajectories over time between genotypes and sexes, a linear mixed model was fitted using the lme function from the nlme statistical package (https://cran.r-project.org/ package $=$ nlme) in R. A B-spline (with $5 \mathrm{Df}$ ) for time was fitted as a fixed effect using the bs function from the 


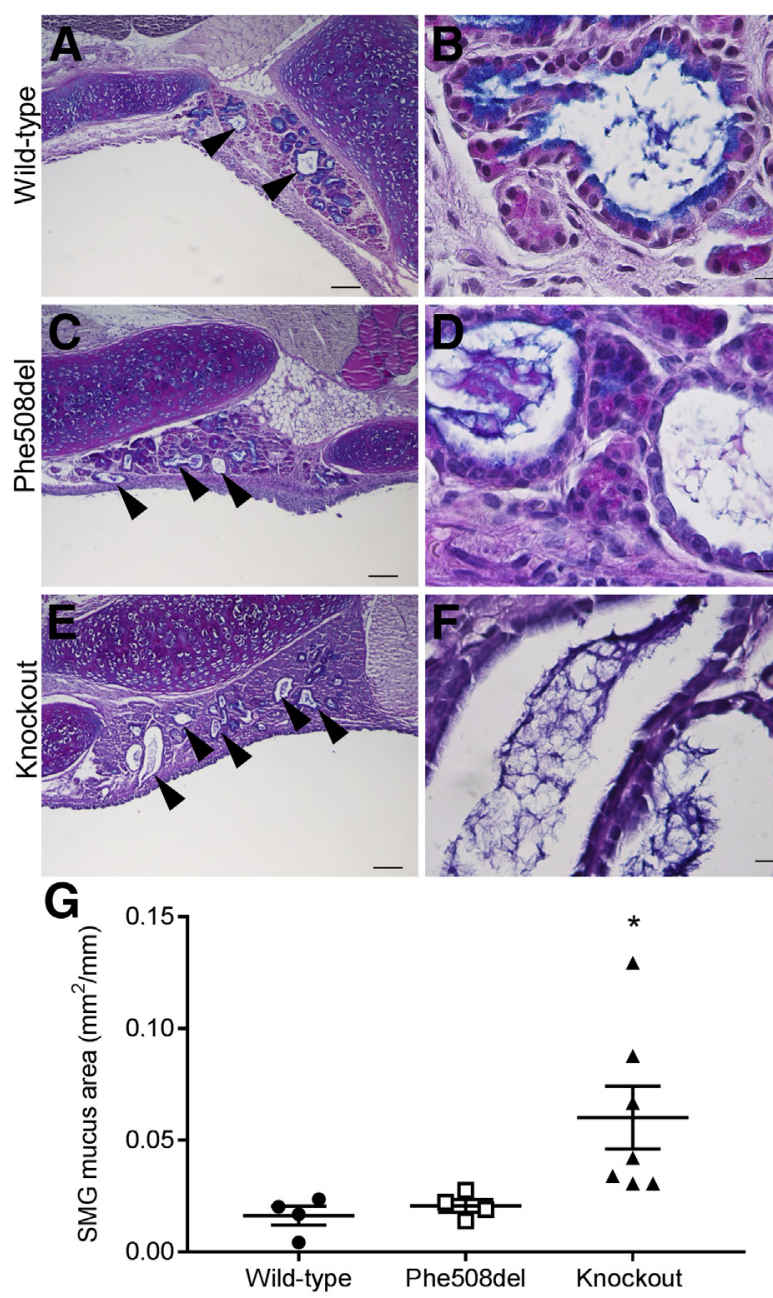

Figure 6 Trachea histology and submucosal gland area quantification in Phe508del and knockout (K0) rats. A-D: Histology (Alcian blue periodic acid-Schiff stained) of the trachea from 1-month-old rats. $\mathbf{A}$ and $\mathbf{B}$ : Normally developed trachea tissue in wild-type (WT) rats with occasional dilated submucosal glands (SMGs). C and D: Phe508del rats demonstrate submucosal gland dilation at a similar frequency to the wild-type rats. $\mathbf{E}$ and $\mathbf{F}$ : $\mathrm{KO}$ rats show abundant dilated submucosal glands filled with mucus material. Arrowheads indicate dilated submucosal glands. . G: Morphometric quantification of the submucosal gland mucus area. Data are expressed as means \pm SEM (G). $n=4$ to 7 animals per group (A-G). ${ }^{*} P<0.05$ versus WT (one-way analysis of variance). Scale bars: $100 \mu \mathrm{m}$ $(\mathbf{A}, \mathbf{C}$, and $\mathbf{E}) ; 10 \mu \mathrm{m}(\mathbf{B}, \mathbf{D}$, and $\mathbf{F})$.

splines package (R Core Team 2019) to model the nonlinear relationship of weight over time. Genotype (wild-type, Phe508del, or knockout) and sex (female or male) were also fitted as fixed effects, as well as all possible interactions between fixed effects. Time nested within rat identification number was fitted as a random effect. The within-subject variance was estimated separately for each sex to allow for heterogeneity in weight across the sexes. The fixed effects were examined using likelihood ratio tests, including assessment of interactions. Tukey's honestly significant difference pairwise multiple comparisons of genotypes at each time point for each sex were performed using the emmeans statistical package (https://cran.r-project.org/ web/packages/emmeans) in R. Results are shown as the estimated mean weight at each time point and associated 95\% CIs.

For survival analysis, Kaplan-Meier survival curves were plotted in GraphPad. The survdiff function from the survival statistical package (https://cran.r-project.org/package = survival) in $\mathrm{R}$ software version $3.6 .1^{31}$ was used to compute the log-rank test to compare the survival curves. Pairwise comparisons between groups were performed using the pairwise_survdiff function from the survminer statistical package (https://cran.r-project.org/web/packages/ survminer) in R. Other normally distributed outcome variables were analyzed using one-way analysis of variance with Dunnett's multiple comparisons test, where $P \leq 0.05$ was considered statistically significant.

\section{Results}

\section{Phe508del and K0 Founders Were Generated Using CRISPR/Cas9}

Of the 30 pups born (from 90 transplanted embryos), six animals $(20 \%)$ were identified to be carrying at least one mutant allele within a 187-bp region of exon 11 (surrounding the TTT deletion site). Two $(6.7 \%)$ of the screened animals were identified as having the TTT deletion. One rat had an allele that contained the desired homology-directed repair edited TTT deletion and was designated the Phe508del founder (c.1522_1524delTTT). The second rat also harbored an allele with the TTT deletion. However, this rat was a mosaic, containing two alleles with undesired mutations and, therefore, was not used for breeding. A rat with an 8-bp deletion upstream of the TTT site (c.1514_1521delATATCATC) was used to establish the KO strain. This mutation causes a frameshift after amino acid 505, resulting in the introduction of a premature termination codon at position 510. The remaining three mutant pups harbored various nonhomologous end joining-repaired alleles and were not used for breeding. Selected founders were mated with wild-type SpragueDawley rats to produce heterozygous breeding pairs that were subsequently used to breed CF rats.

\section{Breeder Rats Have Normal Reproduction Rates}

For Phe508del breeding, three heterozygous Phe508del $\times$ homozygous Phe508del breeding pairs gave birth to 158 pups in 16 litters, with a mean litter size of 9.8 pups. For KO breeding, seven heterozygous breeding trios gave birth to 306 pups in 26 litters, with a mean of 11.7 pups per litter. The litter sizes were comparable to wild-type Sprague-Dawley breeding (mean litter size of 10.2 pups). When using homozygous Phe508del females and heterozygous males for breeding, the ratio of $\mathrm{CF} /$ heterozygous pups was close to the expected 1:1 ratio. Similarly, when using heterozygous female and male pairings for the 


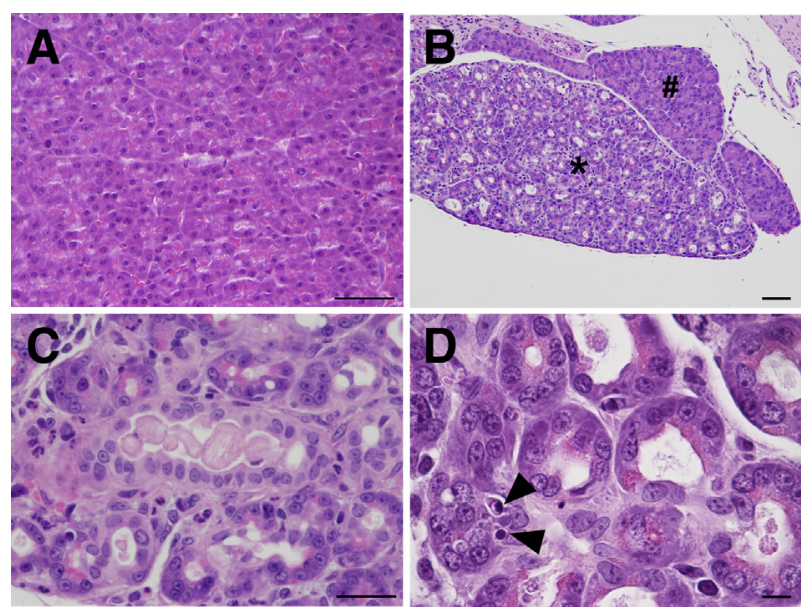

Figure 7 Pancreas histopathology in knockout (KO) rats. Hematoxylin and eosin-stained pancreas sections from 1-month-old rats. A: Normal pancreas histology in wild-type rat. B: Pancreas from $\mathrm{KO}$ rat with focal degeneration of the exocrine pancreas (asterisk) adjacent to normally developed pancreatic tissue (hash mark). C: Pancreatic duct filled with eosinophilic secretions. D: Apoptotic bodies within acinar cells indicated by arrowheads. $n=8$ animals per genotype (A-D). Scale bars: $50 \mu \mathrm{m}$ (A and C); $10 \mu \mathrm{m}$ (B and D).

KO breeding, the ratio was approximately 1:2:1 (wild type/heterozygous/CF). The genotype distribution for both CF rat strains is outlined in Table 2.

\section{Growth Trajectories Are Reduced in Phe508del and $\mathrm{KO}$ Rats}

The linear mixed model analysis of body weight data showed that the growth trajectories differ significantly between wild-type, Phe508del, and KO rats for both males and females $\left(\mathrm{F}_{10,1449}=12.60 ; P<0.0001\right)$. The fitted splines for each genotype and sex are shown in Figure 1. Pairwise comparisons revealed that from 1.25 months of age onwards, the estimated mean body weights for Phe508del and KO were significantly lower than wild-type, with the exception of female Phe508del rats, where the estimated mean body weight did not become significantly lower than wild-type until 2 months of age. In addition to this, $\mathrm{KO}$ rats of both sexes had a significantly reduced estimated mean body weight when compared with Phe508del rats. These differences in body weight were maintained for all genotypes and sexes until 6 months of age, apart from female Phe508del rats, where the difference was no longer statistically significant from wild-type after 3.5 months.

\section{Survival Is Impaired in Phe508del and K0 Rats}

The survival of both Phe508del and KO rats is significantly reduced when compared with wild-type animals $(P<0.0001)$ (Figure 2$)$. KO rats are more severely affected, demonstrating a significantly lower survival when compared with Phe508del rats. By 1 week of age, the proportion of surviving Phe508del and KO pups is decreased compared with wild-type ( $84 \%$ versus $60 \%$ survival, respectively). Early death is attributed to meconium ileus (MI) and failure to thrive. Around the time of weaning (21 days) until approximately 2 months of age, both Phe508del and KO rats demonstrated further reductions in survival, typically due to gastrointestinal obstructions and poor weight gain. By approximately 2 months of age, $66 \%$ of Phe508del rats and $34 \%$ of $\mathrm{KO}$ rats remained. After this stage, survival plateaued for both genotypes, with no deaths observed from this point onwards.

\section{CFTR mRNA Is Reduced in the Lungs of KO Rats while Phe508del Levels Are Unaffected}

RNAscope in situ hybridization was performed to localize CFTR mRNA in the lungs of wild-type and CF rats. RNAscope analyses demonstrated that CFTR mRNA was robustly expressed in the bronchi and small airway epithelium of wild-type rats, as well as in the alveolar regions, where it localized to type II pneumocytes. Phe508del rats showed similar CFTR mRNA levels and localization patterns when compared with wild-type, whereas $\mathrm{KO}$ rats exhibited lower CFTR mRNA expression in the airways and alveolar tissue (Figure 3, A-I). Quantification of CFTR mRNA molecules revealed that Phe508del levels did not differ from wild-type, whereas KO transcripts were significantly reduced $(P<0.05)$ (Figure $3 \mathrm{~J}$ ).

Quantitative real-time PCR was performed to measure CFTR mRNA expression in the lung tissue. Consistent with the RNAscope findings, CFTR mRNA levels in Phe508del rat lungs were approximately $61.2 \%$ of wild-type levels, with no statistically significant difference observed. This is comparable to humans with the Phe508del mutation, where the level of $C F T R$ transcripts is similar to that of non-CF. ${ }^{32}$ CFTR mRNA expression was significantly reduced in $\mathrm{KO}$ rats, with levels present at $23.6 \%$ of wild-type $(P<0.001)$ (Figure 3K).

\section{Immunostaining Reveals Reduced CFTR and Differential Localization in Phe508del and K0 Rats}

CFTR was highly expressed in the bronchioles of wildtype rats, whereas Phe508del and KO rats had reduced CFTR expression. Enlarged images show that in wild-type animals, most cells lining the bronchiole express CFTR on their apical surface. In contrast, CFTR expression in Phe508del and KO rats displayed cytoplasmic localization with intense punctate staining. KO expression of CFTR was also found to have a lower proportion of CFTRpositive cells lining the bronchioles. The University of North Carolina CFTR-knockout mouse negative control tissue exhibited no CFTR staining. The secondary antibody-only control was also negative for CFTR staining (Figure 4A). Dual staining using lysosomal-associated membrane protein 1 demonstrates that CFTR colocalizes 


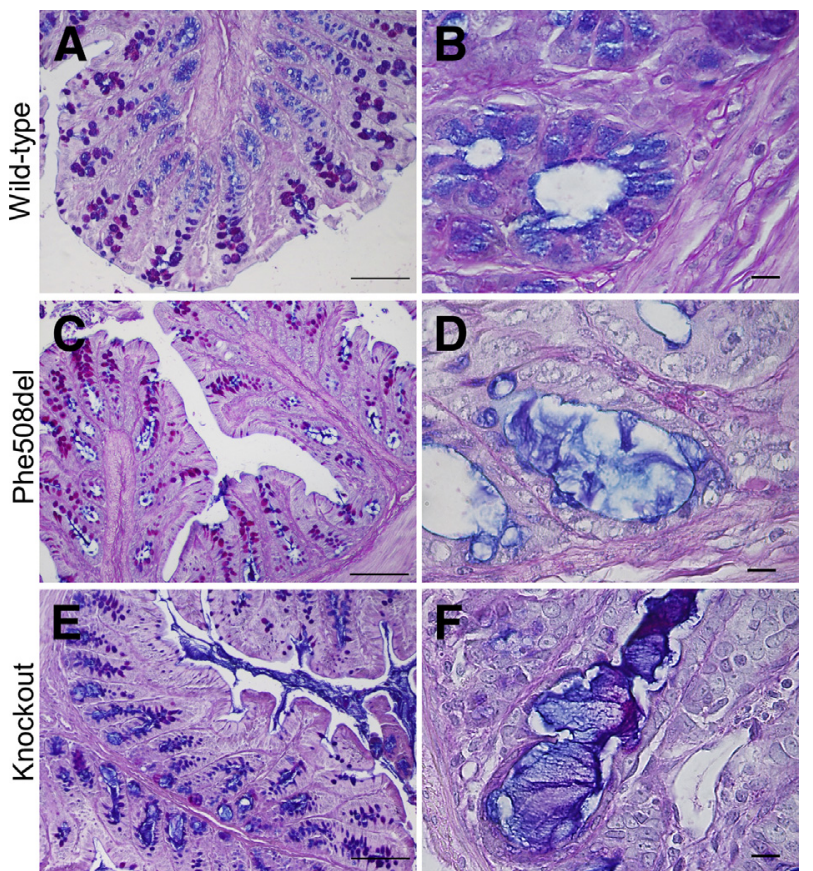

Figure 8 Large intestine histology in Phe508del and knockout (K0) rats. Alcian blue periodic acid-Schiff-stained large intestine sections from 1-month-old rats. A and B: Normally developed large intestine in wild-type rat with absence of mucus in the crypts. $\mathbf{C}$ and $\mathbf{D}$ : Phe508del rats show mild crypt dilation with small amounts of mucus. $\mathbf{E}$ and $\mathbf{F}$ : KO rats exhibit abundant mucus in markedly dilated crypts, with mucus extrusion into the lumen frequently observed. $n=8$ animals per genotype $(\mathbf{A}-\mathbf{F})$. Scale bars: $100 \mu \mathrm{m}(\mathbf{A}, \mathbf{C}$, and $\mathbf{E}) ; 10 \mu \mathrm{m}(\mathbf{B}, \mathbf{D}$, and $\mathbf{F})$.

to the lysosome in both Phe508del and $\mathrm{KO}$ rats (Figure 4B).

\section{Hematology and Serum Chemistry Parameters Are Unaffected in CF Rats}

Total white blood cell count and differentials were not different between wild-type, Phe508del, and KO animals (Supplemental Table S1). Red blood cell, hemoglobin, and hematocrit levels were also unchanged. Mean corpuscular hemoglobin levels were significantly higher in $\mathrm{KO}$ animals $(P<0.05)$ but were still within normal range. There were no significant changes in most of the serum biochemistry analytes. Interestingly, the levels of liver enzyme alkaline transferase were significantly increased in the KO animals compared with wild-type $(P<0.05)$; however, all alkaline transferase levels were above the reference range for Sprague-Dawley rats, and there was no histologic evidence of hepatocellular injury.

\section{Bioelectric Defects Are Present in the Nasal Airways of Phe508del and K0 Rats}

The transepithelial voltage across the nasal airway surface was measured to characterize the airway bioelectric profile. KO rats demonstrated classic CF electrophysiological defects in the nasal respiratory epithelium, whereas Phe508del rats showed an intermediate phenotype (Figure 5). Under basal conditions, $\mathrm{KO}$ and Phe508del rats demonstrated a significantly more negative baseline potential difference when compared with wild-type animals, with this parameter more pronounced in $\mathrm{KO}$ rats. Both Phe508del and KO rats exhibited an enhanced depolarization response to perfusion of the epithelial sodium channel inhibitor amiloride, indicating the presence of increased sodium absorption in the nasal airways. Wildtype animals, on the other hand, showed an expected small depolarization response.

Perfusion of a low-chloride solution produced marked hyperpolarization in wild-type rats, indicating robust CFTR function in the nasal airways. Comparatively, the hyperpolarization response in Phe508del rats was blunted and depolarization was observed in $\mathrm{KO}$ rats. $\mathrm{KO}$ rats also exhibited a minimal $\triangle \mathrm{PD}$ to perfusion of cAMP agonist isoproterenol when compared with WT rats, suggesting an absence of CFTR-mediated chloride transport; however, this effect did not reach statistical significance. Phe508del rats displayed a small hyperpolarization response to CFTR stimulation with isoproterenol, suggesting that although residual CFTR function is present, it is considerably impaired.

\section{Lung, Nasal, and Liver Tissues Are Histologically Normal in Phe508del and K0 Rats}

The lung tissues of Phe508del and KO rats showed no evidence of histopathology at 1 month of age (Supplemental Figure S1). Furthermore, bronchoalveolar lavage cell profiles did not exhibit any differences between Phe508del, $\mathrm{KO}$, and wild-type rats, indicating a lack of inflammation in the lungs of both CF rat models (data not shown). Microscopically, nasal and liver tissues from Phe508del and KO rats at 1 month of age also appeared normally developed (Supplemental Figures S2 and S3).

\section{Tracheal Tissue Is Histologically Abnormal in KO Rats}

Macroscopically, the trachea of both CF rat models appeared normally developed. Histologically, KO rats frequently showed dilated submucosal gland lumina containing abundant mucus secretion, the identity of which was confirmed by Alcian blue periodic acid-Schiff staining. In addition, KO rats exhibited increased numbers of dilated submucosal glands. Phe508del and wild-type rats also demonstrated occasional dilation of the submucosal glands with eosinophilic, protein-like material, a previously reported normal finding in rats (Figure 6, A-F). ${ }^{33}$ Morphometric measurements of trachea section images confirmed these observations, with $\mathrm{KO}$ rats exhibiting a significantly larger submucosal gland mucus area when compared with wild-type and Phe508del rats $(P<0.05)$ (Figure 6G). 

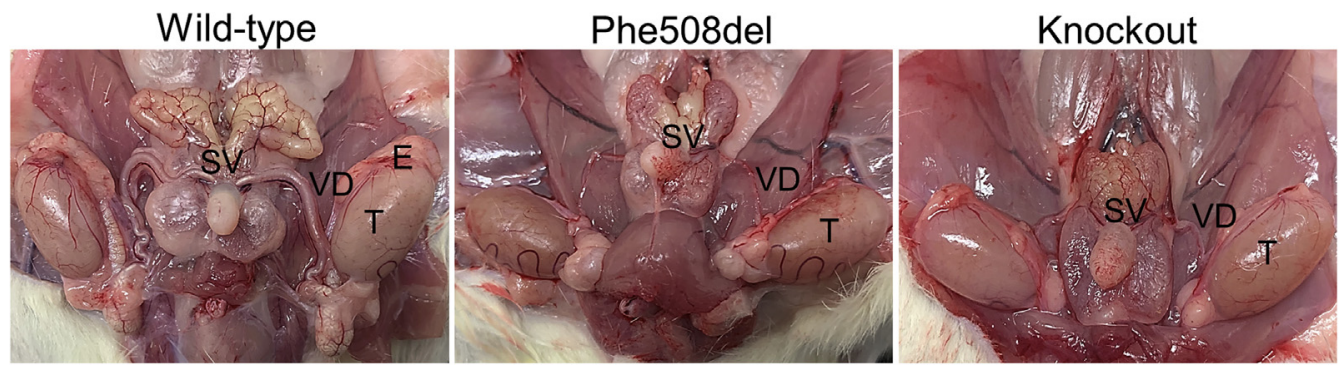

Figure 9 Male reproductive tract anatomy in Phe508del and knockout (KO) rats. Phe508del and K0 rats lack properly formed vas deferens (VD) and seminal vesicles (SVs), and epididymides (E) are not observable in either cystic fibrosis rat model. $n=3$ animals per group. T, testis.

\section{KO Rats Exhibit Disease of the Exocrine Pancreas}

Macroscopically, the pancreas of both Phe508del and $\mathrm{KO}$ rats was indistinguishable from wild-type rats. Histologically, the pancreas of Phe508del rats was normally developed, whereas approximately $25 \%$ of $\mathrm{KO}$ rats exhibited multifocal degeneration of the exocrine pancreas. The exocrine pancreatic histopathology observed in a proportion of $\mathrm{KO}$ rats was characterized by apoptosis of acinar cells, forming apoptotic bodies and necrosis, desquamation of cellular debris into dilated lumina, and occasional ducts distended by eosinophilic, proteinaceous secretion (Figure 7). These lesions are similar to those observed in early human CF pancreatic disease. ${ }^{34-36}$ The endocrine tissue (islets of Langerhans) did not appear to be affected in either Phe508del or KO rats.

\section{Phe508del and K0 Rats Demonstrate Lethal Intestinal Obstruction}

Gastrointestinal obstruction is common in all reported CF animal models, including mice, ${ }^{37}$ rats, ${ }^{7}$ ferrets, ${ }^{38}$ pigs, ${ }^{39}$ and sheep. ${ }^{8}$ During the early neonatal period, both Phe508del and $\mathrm{KO}$ rats experienced mortality due to meconium ileus. KO rats had a higher occurrence of MI, with $40 \%$ affected compared with $16 \%$ of Phe508del rats. Rat pups with MI were substantially smaller than their littermates and presented with dark and distended abdomens, had dehydration, as indicated by skin tenting, and often lacked a milk band, suggesting that they had not fed. At post-mortem, obstruction was observed in the small intestine, which consisted of tenacious meconium. After weaning to solid food and up until 2 months of age, CF rats exhibited another wave of mortality that was attributed to intestinal obstruction.

\section{Phe508del and K0 Rats Exhibit Colonic Crypt Dilation and Mucus Accumulation}

The small intestine (duodenum and ileum) appeared histologically normal in both rat models, whereas the large intestine demonstrated some histopathologic features. KO rats exhibited markedly dilated crypts that were often distended with mucus. Mucus extrusion into the lumen of the large intestine was frequently observed and was often overlying the mucosal surface. Although Phe508del rats also demonstrated this pathology, it was typically milder in nature, with fewer and smaller dilated crypts and only occasional mucus extrusion into the lumen. In both CF rat models, the intestinal crypts were found to be dilated with Alcian blue periodic acid-Schiff positive mucin (Figure 8).

\section{Male Phe508del and K0 Rats Exhibit Reproductive Tract Malformations}

Analysis of the male reproductive tract showed significant morphologic differences in Phe508del and KO rats when compared with their wild-type counterparts. Phe508del and $\mathrm{KO}$ rats exhibited a marked reduction in the size of the vas deferens and seminal vesicles, whereas the epididymides were unobservable (Figure 9). Isolation of cauda epididymal sperm from the vas deferens indicated that Phe508del rats had normal to moderate sperm levels; however, a proportion of rats exhibited sperm abnormalities, with separation of the tail and head observed. KO rats, on the other hand, had a

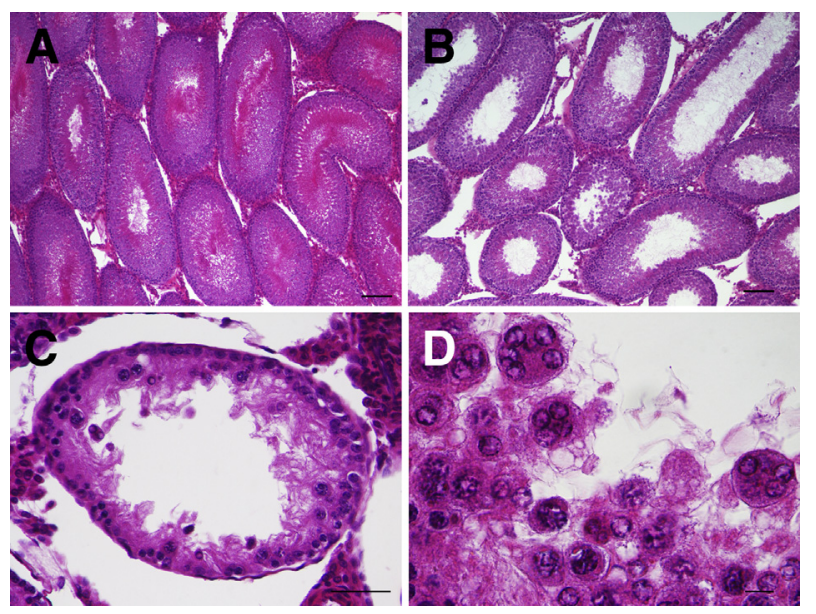

Figure 10 Testicular histology in Phe508del and knockout (K0) rats. Hematoxylin and eosin-stained testicular sections from 8- to 12-week-old rats. A: Normally developed testis tissue in wild-type rat. B-D: Phe508del and $\mathrm{KO}$ rats demonstrate testicular degeneration and reduced sperm abundance (B), diminished germinal epithelium in the seminiferous tubules (C), and multinucleated giant cells in the lumina of some tubules (D). The extent of tubule degeneration was variable between animals of the same genotype. $n=3$ animals per group (A-D). Scale bars: $100 \mu \mathrm{m}$ (A and B); $50 \mu \mathrm{m}$ (C); $10 \mu \mathrm{m}$ (D). 


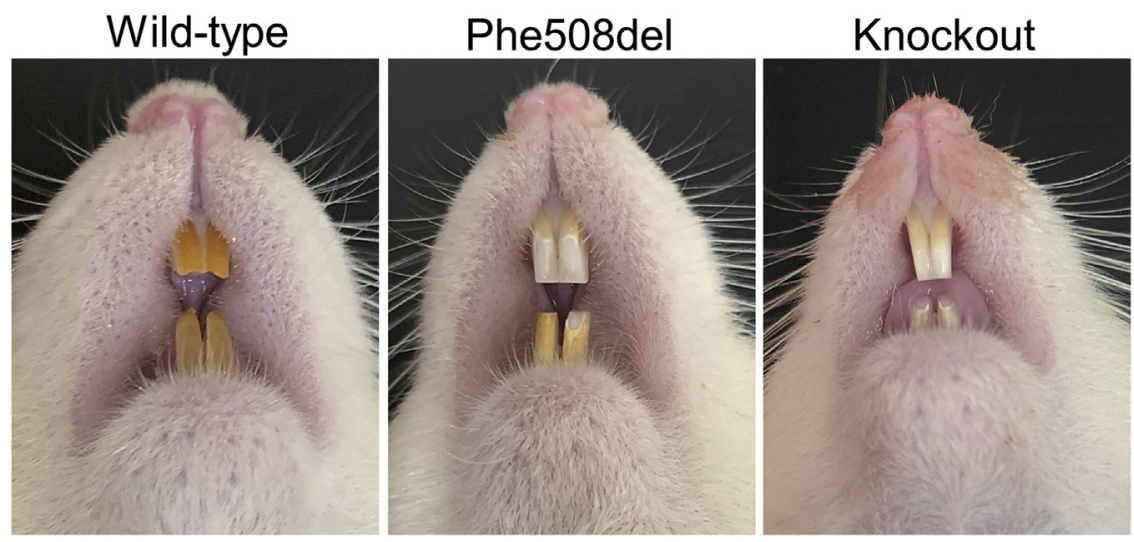

Figure 11 Dentition in Phe508del and knockout (KO) rats. A lack of incisor enamel pigmentation is observed in both Phe508del and $\mathrm{K} 0$ rat strains. Wild-type rats exhibit characteristic yellow-brown enamel, whereas Phe508del rats demonstrate yellow-white enamel and $\mathrm{KO}$ rats demonstrate bright white incisors. $n=3$ animals per group.

complete absence of cauda epididymal sperm (data not shown).

Although the Phe508del and KO rat testes appeared macroscopically normal, the tone of the testis on palpation was soft as opposed to the firm testis from the wild-type rats. Microscopically, in both Phe508del and $\mathrm{KO}$ rats, seminiferous tubules were reduced in size and there was disorganization, degeneration, and exfoliation of germinal epithelial cells, which were often diminished in number. Multinucleated giant cells, derived from spermatid coalescence, were abundant in the lumen of some tubules. This testicular degeneration resulted in disrupted spermatogenesis and a marked paucity of spermatozoa. In a few seminiferous tubules, germ cells were markedly depleted, with only basal Sertoli cells and occasional spermatogonia remaining (Figure 10).

\section{Phe508del and K0 Rats Demonstrate Abnormal Dentition}

Both CF rat strains demonstrated abnormal dentition, as has been previously observed in CF mouse models ${ }^{40}$ and the US-generated $\mathrm{KO}$ rat model. ${ }^{7}$ Compared with wild-type animals that demonstrate normal yellow-brown incisor enamel, both $\mathrm{CF}$ rat strains lack enamel pigmentation. $\mathrm{KO}$ rats exhibit bright white enamel, and Phe508del rats appear to show an intermediate phenotype of yellow-white teeth (Figure 11). Rats from both genotypes have a tendency to develop grossly malformed teeth that become curved and overgrown, requiring regular incisor trimming.

\section{Discussion}

Advances in gene modification technologies have enabled the development of a range of CF animal models, including mice, ferrets, pigs, sheep, and rabbits. Although these animals are proving useful for a range of mechanistic and therapeutic studies, ${ }^{21,41-43}$ species such as ferrets, pigs, and sheep have severe disease phenotypes, require costly and labor-intensive husbandry, and cannot be imported into
Australia because of quarantine and licensing restrictions. Rats were selected because of the logistical advantages of breeding and rearing, and evidence of a mild lung disease phenotype in US-generated $\mathrm{KO}$ rats $^{7,14}$ that permits longitudinal assessments of therapies. In addition to the existing CFTR KO paradigm, this study generated the first CF rat model bearing the common Phe508del mutation to provide an in vivo platform for investigating Phe508del-specific disease mechanisms and treatments, including pharmacologic agents and genetic therapies.

The characterization from this investigation found that Phe508del rats consistently exhibited milder disease phenotypes when compared with $\mathrm{KO}$ rats. In the airways, the CFTR-Phe508del protein showed predominant cytoplasmic staining that was localized with the lysosome, indicating protein degradation. This finding is consistent with the human equivalent, where peripheral protein quality control systems remove CFTR-Phe508del from the cell surface for lysosomal degradation. ${ }^{44}$ The nasal potential difference profile of the Phe508del rat indicated low-level CFTR-mediated chloride transport in the nasal airways. It is, therefore, likely that a fraction of rat CFTR-Phe508del mRNA is partially processed, allowing mutant CFTR to reach the apical membrane and retain partial function as a chloride channel. Although this level of CFTR function is not sufficient to prevent disease altogether, it may explain the milder disease phenotype observed in Phe508del rats when compared with KO. The Phe508del mutation is known to result in severe disease in humans, differing from the mild phenotype observed herein in the rat. This disparity could partly be explained by species differences in the processing and function of CFTR-Phe508del protein. In a previous study, ${ }^{45}$ the CFTR-Phe508del processing defect was found to be more severe in humans when compared with pigs or mice. Unlike with human CFTR-Phe508del protein, mutant pig and mouse CFTR was found to be partially processed, resulting in residual transepithelial chloride transport, which is also likely the case for the Phe508del rat.

$\mathrm{KO}$ rats demonstrated greater disease severity across all described phenotypes, which aligns with quantitative PCR, RNAscope, immunohistochemical, and nasal potential 


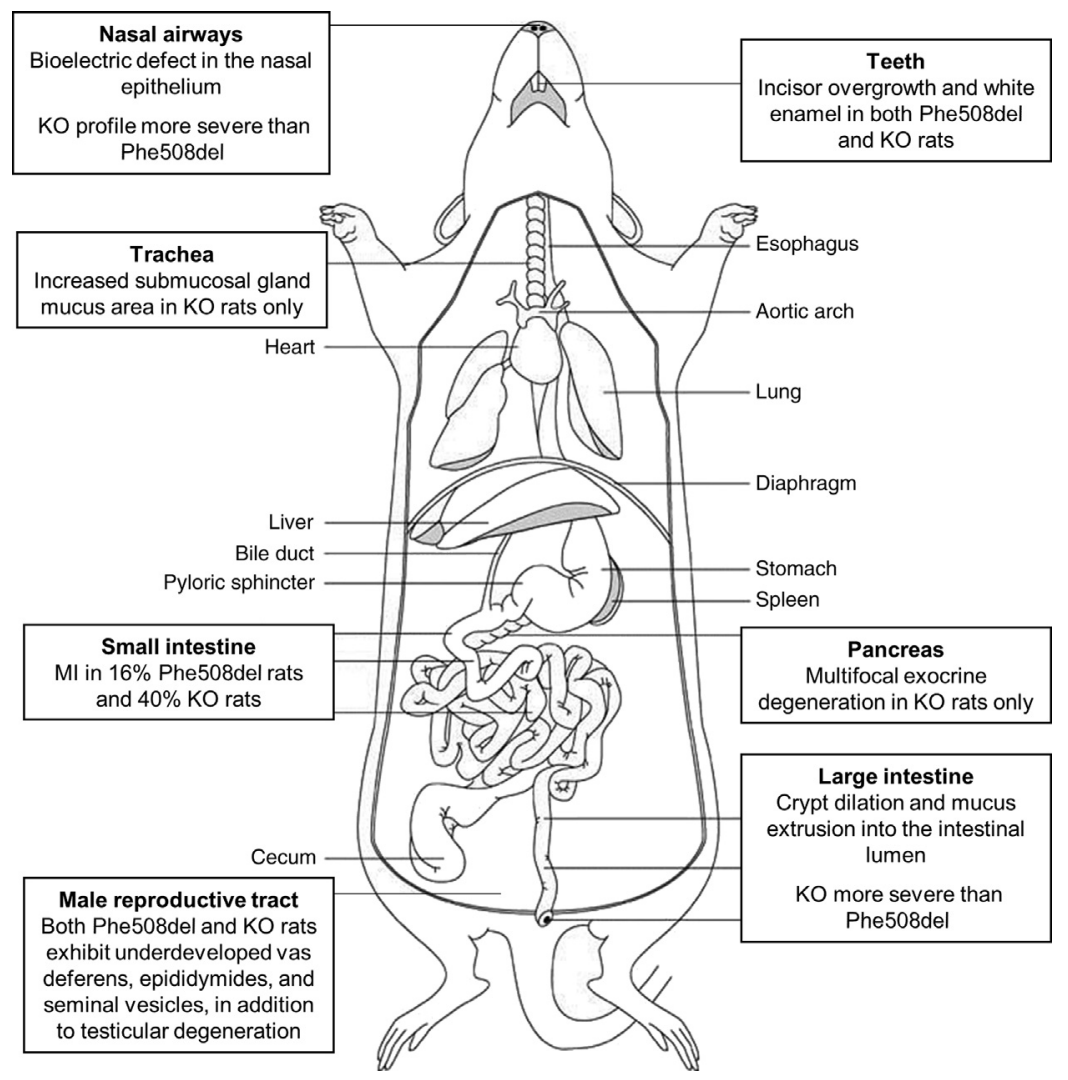

Figure 12 Schematic diagram indicating the cystic fibrosis phenotypes observed in Phe508del and knockout (KO) rats. difference findings. KO rats had significantly reduced lung CFTR mRNA levels, likely because of the triggering of nonsense-mediated mRNA decay. Accordingly, CFTR protein levels were also substantially decreased in the airways, and the protein that was produced was truncated because of the presence of a premature stop codon, thus leading to a loss of CFTR function. The cytoplasmic presence of CFTR in KO airways suggests that some transcripts escape nonsense-mediated decay, a phenomenon that is present in human CFTR mutations, such as 3905insT. ${ }^{46}$ As in Phe508del rats, KO CFTR was also colocalized with the lysosome, indicating degradation of the truncated protein. The lack of critical functional domains of the CFTR protein, in conjunction with the nasal potential difference profile indicating loss of CFTR function, suggests that although the CFTR protein is present, the function is lost, leading to generation of a more severe $\mathrm{CF}$ phenotype.

To the knowledge of the authors, this is the first study to assess CFTR mRNA localization in rat lungs using RNAscope in situ hybridization. These results revealed that CFTR mRNA is expressed robustly in cartilaginous and intrapulmonary airways of wild-type rats and localizes to type II pneumocytes, which has been observed in human adult lungs. ${ }^{47}$ Comparatively, wild-type mice have low endogenous CFTR mRNA expression in the airways. ${ }^{48}$ The high level of CFTR mRNA observed herein in wild-type rats provides an advantage over the use of mouse models for CFTR-related investigations.

Rats exhibit naturally high numbers of submucosal glands throughout the trachea and bronchi, resembling those of humans. ${ }^{23,33}$ This is an advantage for a CF rat model given that serous cells of the submucosal glands express high levels of CFTR and the glands themselves are implicated in the development of human CF airway disease. ${ }^{24,49}$ In this study, KO rats exhibited excess submucosal gland mucus production and accumulation, whereas Phe508del rats did not. This phenomenon in KO rats may be explained by a complete loss of CFTR-mediated anion transport in serous cells and a subsequent reduction in secretion of fluid, which, in turn, leads to viscous mucus in the lumen of the glands. ${ }^{49-51}$ Mucus-filled submucosal glands are considered an early sign of CF lung disease, with this histology observed in the tracheae of human fetuses. ${ }^{49,52}$ As human CF lung disease progresses, the submucosal glands become hypertrophied along with mucus plugging of the airways. ${ }^{24}$ To date, overt signs of lung disease, such as mucus plugging, inflammation, and bronchiectasis, have not been observed in young Phe508del or KO rats, although it is currently unknown how the submucosal gland defect present in KO rats influences airway disease progression with age. Interestingly, US-generated $\mathrm{KO}$ rats also demonstrate defects in the tracheal submucosal glands; however, this pathology was not apparent until 6 months of age. ${ }^{14}$ 
Phe508del and KO rats demonstrate lethal gut obstructions during two developmental stages: the first week of the neonatal period and from post-weaning up until approximately 2 months of age. Interestingly, US-generated KO rats have not been reported to demonstrate MI during the neonatal phase; however, they do appear to develop post-weaning intestinal obstruction, ${ }^{7}$ as was observed herein. As reported in humans and other CF animal models $^{3,38,39}$ - except for CFTR KO pigs, where $100 \%$ of animals are affected-variable penetrance of $\mathrm{MI}$ is observed in both CF rat models. In this study, neonatal MI affected $40 \%$ of KO and $16 \%$ of Phe508del rats, similar to the $15 \%$ incidence observed in humans. ${ }^{53}$ Studies in humans and mice indicate that modifier genes are likely to be responsible for incomplete penetrance of MI. ${ }^{54-56}$ In addition to MI, both rat models demonstrated colonic crypt obstruction with mucoproteinaceous secretions. This intestinal histopathology is frequently observed in humans as well as CF animal models, including the US-generated $\mathrm{KO}$ rat and CF mouse models. ${ }^{7,57,58}$

At the histologic level, the exocrine pancreas of 1-month-old KO rats demonstrated multifocal degeneration of acinar cells, whereas the tissue of Phe508del rats appeared normally developed. It is currently unknown whether this pathology in 1-month-old KO rats advances with age, as is observed in human disease, where the pancreas undergoes acinar destruction, inflammation, fibrosis, and fatty infiltration. ${ }^{59}$ Pancreatic phenotypes are highly variable between CF animal models. Mouse models were initially thought to lack pancreatic disease; however, some reports have described mild age-related exocrine pancreas manifestations in congenic $\mathrm{KO}$ mice. ${ }^{60} \mathrm{CF}$ sheep and pigs both possess severe pancreatic disease, with advanced atrophy of the exocrine pancreas present at birth. ${ }^{8,39,57} \mathrm{CF}$ ferrets display a pancreatic phenotype most similar to the human course of disease, with a mild pancreatic disease at birth characterized by multifocal areas of dilated acinar cells and subsequent age-related pancreatic destruction. ${ }^{38}$ Interestingly, pancreatic histopathology has not been reported in the US-generated KO model. ${ }^{7}$ Similar to the findings from this study, Phe508del pigs and Phe508del mice demonstrate less severe pancreatic destruction or no pancreatic pathology, respectively, when compared with their KO counterparts. ${ }^{41,60,61}$

Only $25 \%$ of assessed 1-month-old KO rats exhibited multifocal degeneration of the exocrine pancreas. The incomplete penetrance of pancreatic pathology could be explained by the influence of modifier genes that protect some animals from loss of CFTR function in the exocrine pancreas. ${ }^{38}$ In human CF disease, MI is almost exclusively observed in individuals with exocrine pancreatic insufficiency. ${ }^{54,62}$ Accordingly, the low prevalence of pancreatic pathology at 1 month of age may be attributed to premature death of rats with MI that would otherwise go on to develop pancreatic disease. Future studies assessing the presence of pancreatic histopathology in pups that die neonatally from MI are warranted to further examine this phenomenon. Furthermore, longitudinal studies are required to determine whether pancreatic pathology appears in older Phe508del rats. The pancreas disease modeled in $\mathrm{KO}$ rats could provide a platform for investigating early disease pathogenesis.

Both CF rat models demonstrate malformations of the male reproductive tract, including hypoplasia of the vas deferens and seminal vesicles and an absence of the epididymides. These observations are similar to the $\mathrm{CF}$ human phenotype of congenital bilateral absence of the vas deferens. The hallmarks of congenital bilateral absence of the vas deferens include atresia of the vas deferens and atrophy or absence of the epididymides and seminal vesicles, which results in obstructive azoospermia and renders the patient infertile. ${ }^{63}$ In addition to anatomic abnormalities, this study also reports that testicular development and spermatogenesis are impaired in Phe508del and KO rats. CFTR is known to be expressed in human testes, yet histologic examinations from males with $\mathrm{CF}$ and congenital bilateral absence of the vas deferens have yielded variable results, ranging from normal spermatogenesis to significantly reduced sperm counts and sperm abnormalities. ${ }^{64,65}$ Although progress has been made in understanding CF male infertility, the underlying mechanisms of congenital bilateral absence of the vas deferens pathogenesis and the role of CFTR in sperm maturation are yet to be fully understood. ${ }^{66}$ Accordingly, Phe508del and KO CF rat models could provide a novel platform for elucidating the physiological mechanisms of CF male infertility.

In summary, both Phe508del and $\mathrm{KO}$ rat models recapitulate a range of $\mathrm{CF}$ phenotypes (Figure 12). These characteristics include impaired survival, reduced weight gain, intestinal obstruction, bioelectric defects in the nasal epithelium, tooth malformations, and male reproductive tract abnormalities. Histopathologically, Phe508del and KO rats exhibited colonic crypt dilation due to excess extruded mucus, whereas $\mathrm{KO}$ rats also demonstrated topographically increased submucosal gland mucus secretion in the trachea and multifocal degeneration of the exocrine pancreas. CF lung pathology was not observed in either rat model at 1 month of age, and longitudinal studies assessing disease progression over time are in progress. Given that these rats are housed under clean conditions, future studies will investigate lung pathogen challenges with CF-relevant bacterial, viral, and fungal pathogens as these may be necessary to generate $\mathrm{CF}$ lung pathology.

These rat models will provide novel platforms for trialing therapeutics and elucidating the complexities of $\mathrm{CF}$ pathogenesis. In particular, the Phe508del model could be used for screening pharmacologic agents, such as CFTR modulator drugs, whereas $\mathrm{KO}$ rats may be employed in trialing mutation-agnostic treatments, such as gene therapies. In addition, access to two $\mathrm{CF}$ rat models with differing CFTR mutations on the same genetic background 
will allow for direct comparisons and investigations into the role of genotype on disease progression and treatment response. Finally, the CRISPR/Cas9 generation of a Phe508del model has provided precedence for the future development of rat models with other human CFTR mutations.

\section{Acknowledgments}

We thank Dr. Susan Birket for providing invaluable advice on cystic fibrosis rat colony establishment, Dr. Hai Tran for providing antibodies for immunohistochemistry, University of Adelaide Laboratory Animal Services for assisting with animal husbandry, University of Adelaide Histological Services for preparing specimen slides, Institute of Medical and Veterinary Science (IMVS) Sequencing Center and Australian Genome Research Facility for conducting DNA sequencing, Gribbles Veterinary Pathology for performing hematology and serum chemistry, and the Monash University node of the Australian Phenomics Network for kindly providing the founder rats.

\section{Supplemental Data}

Supplemental material for this article can be found at http://doi.org/10.1016/j.ajpath.2020.01.009.

\section{References}

1. Collawn JF, Matalon S: CFTR and lung homeostasis. Am J Physiol Lung Cell Mol Physiol 2014, 307:917-923

2. Wang Y, Wrennall JA, Cai Z, Li H, Sheppard DN: Understanding how cystic fibrosis mutations disrupt CFTR function: from single molecules to animal models. Int J Biochem Cell Biol 2014, 52:47-57

3. Grubb BR, Boucher RC: Pathophysiology of gene-targeted mouse models for cystic fibrosis. Physiol Rev 1999, 79:S193-S214

4. Wilke M, Buijs-Offerman RM, Aarbiou J, Colledge WH, Sheppard DN, Touqui L, Bot A, Jorna H, de Jonge HR, Scholte BJ: Mouse models of cystic fibrosis: phenotypic analysis and research applications. J Cyst Fibros 2011, 10:S152-S171

5. Rogers CS, Hao Y, Rokhlina T, Samuel M, Stoltz DA, Li Y, Petroff E, Vermeer DW, Kabel AC, Yan Z, Spate L, Wax D, Murphy CN, Rieke A, Whitworth K, Linville ML, Korte SW, Engelhardt JF, Welsh MJ, Prather RS: Production of CFTR-null and CFTR-Delta F508 heterozygous pigs by adeno-associated virusmediated gene targeting and somatic cell nuclear transfer. J Clin Invest 2008, 118:1571-1577

6. Sun XS, Sui HS, Fisher JT, Yan ZY, Liu XM, Cho HJ, Joo NS, Zhang YL, Zhou WH, Yi YL, Kinyon JM, Lei-Butters DC, Griffin MA, Naumann P, Luo MH, Ascher J, Wang K, Frana T, Wine JJ, Meyerholz DK, Engelhardt JF: Disease phenotype of a ferret CFTR-knockout model of cystic fibrosis. J Clin Invest 2010, 120: $3149-3160$

7. Tuggle KL, Birket SE, Cui X, Hong J, Warren J, Reid L, Chambers A, Ji D, Gamber K, Chu KK, Tearney G, Tang LP, Fortenberry JA, Du M, Cadillac JM, Bedwell DM, Rowe SM, Sorscher EJ, Fanucchi MV: Characterization of defects in ion transport and tissue development in cystic fibrosis transmembrane conductance regulator (CFTR)-knockout rats. PLoS One 2014, 9: e91253
8. Fan Z, Perisse IV, Cotton CU, Regouski M, Meng Q, Domb C, Van Wettere AJ, Wang Z, Harris A, White KL, Polejaeva IA: A sheep model of cystic fibrosis generated by CRISPR/Cas9 disruption of the CFTR gene. JCI Insight 2018, 3:123529

9. Livraghi-Butrico A, Rogers T, Wilkinson MH, Terrell K, Pickles RJ, O'Neal WK, Sun F, Boucher R, Grubb BR: CF rabbits: the UNC experience. Pediatr Pulmonol 2018, 53:S148-S456

10. McCarron A, Donnelley M, Parsons D: Airway disease phenotypes in animal models of cystic fibrosis. Respir Res 2018, 19:54

11. Lavelle GM, White MM, Browne N, McElvaney NG, Reeves EP: Animal models of cystic fibrosis pathology: phenotypic parallels and divergences. Biomed Res Int 2016, 2016:5258727

12. Semaniakou A, Croll RP, Chappe V: Animal models in the pathophysiology of cystic fibrosis. Front Pharmacol 2019, 9:1475

13. Meyerholz DK: Lessons learned from the cystic fibrosis pig. Theriogenology 2016, 86:427-432

14. Birket SE, Davis JM, Fernandez CM, Tuggle KL, Oden AM, Chu KK, Tearney GJ, Fanucchi MV, Sorscher EJ, Rowe SM: Development of an airway mucus defect in the cystic fibrosis rat. JCI Insight 2018, 3:e97199

15. Yan Z, Stewart ZA, Sinn PL, Olsen JC, Hu J, McCray PB, Engelhardt JF: Ferret and pig models of cystic fibrosis: prospects and promise for gene therapy. Hum Gene Ther Clin Dev 2015, 26 : $38-49$

16. Steines B, Dickey DD, Bergen J, Excoffon KJDA, Weinstein JR, Li X, Yan Z, Abou Alaiwa MH, Shah VS, Bouzek DC, Powers LS, Gansemer ND, Ostedgaard LS, Engelhardt JF, Stoltz DA, Welsh MJ, Sinn PL, Schaffer DV, Zabner J: CFTR gene transfer with AAV improves early cystic fibrosis pig phenotypes. JCI Insight 2016, 1: e88728

17. Cooney AL, Abou Alaiwa MH, Shah VS, Bouzek DC, Stroik MR, Powers LS, Gansemer ND, Meyerholz DK, Welsh MJ, Stoltz DA, Sinn PL, McCray PB: Lentiviral-mediated phenotypic correction of cystic fibrosis pigs. JCI Insight 2016, 1:e88730

18. Cmielewski P, Donnelley M, Parsons DW: Long-term therapeutic and reporter gene expression in lentiviral vector treated cystic fibrosis mice. J Gene Med 2014, 16:291-299

19. Alton EWFW, Middleton PG, Caplen NJ, Smith SN, Steel DM, Munkonge FM, Jeffery PK, Geddes DM, Hart SL, Williamson R, Fasold KI, Miller AD, Dickinson P, Stevenson BJ, McLachlan G, Dorin JR, Porteous DJ: Non-invasive liposome-mediated gene delivery can correct the ion transport defect in cystic fibrosis mutant mice. Nat Genet 1993, 5:135-142

20. Grubb BR, Pickles RJ, Ye H, Yankaskas JR, Vick RN, Engelhardt JF, Wilson JM, Johnson LG, Boucher RC: Inefficient gene transfer by adenovirus vector to cystic fibrosis airway epithelia of mice and humans. Nature 1994, 371:802-806

21. Sun X, Yi Y, Yan Z, Rosen BH, Liang B, Winter MC, Evans TIA, Rotti PG, Yang Y, Gray JS, Park SY, Zhou W, Zhang Y, Moll SR, Woody L, Tran DM, Jiang L, Vonk AM, Beekman JM, Negulescu P, Van Goor F, Fiorino DF, Gibson-Corley KN, Engelhardt JF: In utero and postnatal VX-770 administration rescues multiorgan disease in a ferret model of cystic fibrosis. Sci Transl Med 2019, 11:eaau7531

22. Becq F, Mall MA, Sheppard DN, Conese M, Zegarra-Moran O: Pharmacological therapy for cystic fibrosis: from bench to bedside. J Cyst Fibros 2011, 10:S129-S145

23. Smolich JJ, Stratford BF, Maloney JE, Ritchie BC: New features in the development of the submucosal gland of the respiratory tract. $\mathrm{J}$ Anat 1978, 127:223-238

24. Verkman AS, Song Y, Thiagarajah JR: Role of airway surface liquid and submucosal glands in cystic fibrosis lung disease. Am J Physiol Cell Physiol 2003, 284:C2-C15

25. Kopito RR: Biosynthesis and degradation of CFTR. Physiol Rev 1999, 79:S167-S173

26. Cheng SH, Gregory RJ, Marshall J, Paul S, Souza DW, White GA, O'Riordan CR, Smith AE: Defective intracellular transport and 
processing of CFTR is the molecular basis of most cystic fibrosis. Cell 1990, 63:827-834

27. Amaral MD: Processing of CFTR: traversing the cellular maze-how much CFTR needs to go through to avoid cystic fibrosis? Pediatr Pulmonol 2005, 39:479-491

28. He JQ, Sandford AJ, Wang IM, Stepaniants S, Knight DA, Kicic A, Stick SM, Paré PD: Selection of housekeeping genes for real-time PCR in atopic human bronchial epithelial cells. Eur Respir J 2008, 32:755

29. Young JT: Histopathologic examination of the rat nasal cavity. Fundam Appl Toxicol 1981, 1:309-312

30. He Q, Su G, Liu K, Zhang F, Jiang Y, Gao J, Liu L, Jiang Z, Jin M, Xie H: Sex-specific reference intervals of hematologic and biochemical analytes in Sprague-Dawley rats using the nonparametric rank percentile method. PLoS One 2017, 12:e189837

31. Team RC: A Language and Environment for Statistical Computing. Vienna, Austria, R Foundation for Statistical Computing, 2012. 2019

32. Trapnell BC, Chu CS, Paakko PK, Banks TC, Yoshimura K, Ferrans VJ, Chernick MS, Crystal RG: Expression of the cystic fibrosis transmembrane conductance regulator gene in the respiratory tract of normal individuals and individuals with cystic fibrosis. Proc Natl Acad Sci U S A 1991, 88:6565-6569

33. Widdicombe JH, Chen LL, Sporer H, Choi HK, Pecson IS, Bastacky SJ: Distribution of tracheal and laryngeal mucous glands in some rodents and the rabbit. J Anat 2001, 198:207-221

34. Andersen DH: Cystic fibrosis of the pancreas and its relation to celiac disease: a clinical and pathologic study. JAMA Pediatr 1938, 56: 344-399

35. Oppenheimer EH, Esterly JR: Pathology of cystic fibrosis review of the literature and comparison with 146 autopsied cases. Perspect Pediatr Pathol 1975, 2:241-278

36. Porta EA, Stein AA, Patterson P: Ultrastructural changes of the pancreas and liver in cystic fibrosis. Am J Clin Pathol 1964, 42: $451-465$

37. Ratcliff R, Evans MJ, Cuthbert AW, MacVinish LJ, Foster D, Anderson JR, Colledge WH: Production of a severe cystic fibrosis mutation in mice by gene targeting. Nat Genet 1993, 4:35-41

38. Sun X, Olivier AK, Yi Y, Pope CE, Hayden HS, Liang B, Sui H, Zhou W, Hager KR, Zhang Y, Liu X, Yan Z, Fisher JT, Keiser NW, Song Y, Tyler SR, Goeken JA, Kinyon JM, Radey MC, Fligg D, Wang X, Xie W, Lynch TJ, Kaminsky PM, Brittnacher MJ, Miller SI, Parekh K, Meyerholz DK, Hoffman LR, Frana T, Stewart ZA, Engelhardt JF: Gastrointestinal pathology in juvenile and adult CFTR-knockout ferrets. Am J Pathol 2014, 184:1309-1322

39. Meyerholz DK, Stoltz DA, Pezzulo AA, Welsh MJ: Pathology of gastrointestinal organs in a porcine model of cystic fibrosis. Am J Pathol 2010, 176:1377-1389

40. Wright JT, Kiefer CL, Hall KI, Grubb BR: Abnormal enamel development in a cystic fibrosis transgenic mouse model. J Dent Res 1996, 75:966-973

41. Ostedgaard LS, Meyerholz DK, Chen J-H, Pezzulo AA, Karp PH, Rokhlina T, Ernst SE, Hanfland RA, Reznikov LR, Ludwig PS, Rogan MP, Davis GJ, Dohrn CL, Wohlford-Lenane C, Taft PJ, Rector MV, Hornick E, Nassar BS, Samuel M, Zhang Y, Richter SS, Uc A, Shilyansky J, Prather RS, McCray PB Jr, Zabner J, Welsh MJ, Stoltz DA: The delta F508 mutation causes CFTR misprocessing and cystic fibrosis-like disease in pigs. Sci Transl Med 2011, 3:74ra24

42. Pezzulo AA, Tang XX, Hoegger MJ, Abou Alaiwa MH, Ramachandran S, Moninger TO, Karp PH, Wohlford-Lenane CL, Haagsman HP, van Eijk M, Banfi B, Horswill AR, Stoltz DA, McCray PB Jr, Welsh MJ, Zabner J: Reduced airway surface $\mathrm{pH}$ impairs bacterial killing in the porcine cystic fibrosis lung. Nature 2012, 487:109-113

43. Stoltz DA, Meyerholz DK, Pezzulo AA, Ramachandran S, Rogan MP, Davis GJ, Hanfland RA, Wohlford-Lenane C, Dohrn CL, Bartlett JA, Nelson GA, Chang EH, Taft PJ,
Ludwig PS, Estin M, Hornick EE, Launspach JL, Samuel M, Rokhlina T, Karp PH, Ostedgaard LS, Uc A, Starner TD, Horswill AR, Brogden KA, Prather RS, Richter SS, Shilyansky J, McCray PB Jr, Zabner J, Welsh MJ: Cystic fibrosis pigs develop lung disease and exhibit defective bacterial eradication at birth. Sci Transl Med 2010, 2:29ra31

44. Okiyoneda T, Barrière H, Bagdány M, Rabeh WM, Du K, Höhfeld J, Young JC, Lukacs GL: Peripheral protein quality control removes unfolded CFTR from the plasma membrane. Science 2010, 329: 805-810

45. Ostedgaard LS, Rogers CS, Dong QA, Randak CO, Vermeer DW, Rokhlina T, Karp PH, Welsh MJ: Processing and function of CFTRDelta F508 are species-dependent. Proc Natl Acad Sci U S A 2007, 104:15370-15375

46. Sanz J, von Kanel T, Schneider M, Steiner B, Schaller A, Gallati S: The CFTR frameshift mutation 3905insT and its effect at transcript and protein level. Eur J Hum Genet 2010, 18:212-217

47. Engelhardt JF, Zepeda M, Cohn JA, Yankaskas JR, Wilson JM: Expression of the cystic fibrosis gene in adult human lung. J Clin Invest 1994, 93:737-749

48. Livraghi A, Kelly E, Wilkinson K, Rogers T, Gilmore R, Harkema J, Randell S, Boucher R, O'Neal W, Grubb B: Loss of CFTR function exacerbates the phenotype of $\mathrm{Na}+$ hyperabsorption in murine airways. Am J Physiol Lung Cell Mol Physiol 2013, 304:L469-L480

49. Salinas D, Haggie PM, Thiagarajah JR, Song Y, Rosbe K, Finkbeiner WE, Nielson DW, Verkman AS: Submucosal gland dysfunction as a primary defect in cystic fibrosis. FASEB J 2005, 19:431-433

50. Wine JJ, Joo NS: Submucosal glands and airway defense. Proc Am Thorac Soc 2004, 1:47-53

51. Joo NS, Irokawa T, Robbins RC, Wine JJ: Hyposecretion, not hyperabsorption, is the basic defect of cystic fibrosis airway glands. J Biol Chem 2006, 281:7392-7398

52. Ornoy A, Arnon J, Katznelson D, Granat M, Caspi B, Chemke J, Opitz JM, Reynolds JF: Pathological confirmation of cystic fibrosis in the fetus following prenatal diagnosis. Am J Med Genet 1987, 28:935-947

53. Wilschanski M, Durie PR: Pathology of pancreatic and intestinal disorders in cystic fibrosis. J R Soc Med 1998, 91 Suppl 34:40-49

54. Blackman SM, Deering-Brose R, McWilliams R, Naughton K, Coleman B, Lai T, Algire M, Beck S, Hoover-Fong J, Hamosh A, Fallin MD, West K, Arking DE, Chakravarti A, Cutler DJ, Cutting GR: Relative contribution of genetic and nongenetic modifiers to intestinal obstruction in cystic fibrosis. Gastroenterology 2006, 131:1030-1039

55. Dorfman R, Li W, Sun L, Lin F, Wang Y, Sandford A, Paré PD, McKay K, Kayserova H, Piskackova T, Macek M, Czerska K, Sands D, Tiddens H, Margarit S, Repetto G, Sontag MK, Accurso FJ, Blackman S, Cutting GR, Tsui L-C, Corey M, Durie P, Zielenski J, Strug LJ: Modifier gene study of meconium ileus in cystic fibrosis: statistical considerations and gene mapping results. Hum Genet 2009, 126:763-778

56. Henderson LB, Doshi VK, Blackman SM, Naughton KM, Pace RG, Moskovitz J, Knowles MR, Durie PR, Drumm ML, Cutting GR: Variation in MSRA modifies risk of neonatal intestinal obstruction in cystic fibrosis. PLoS Genet 2012, 8:e1002580

57. Olivier AK, Gibson-Corley KN, Meyerholz DK: Animal models of gastrointestinal and liver diseases: animal models of cystic fibrosis: gastrointestinal, pancreatic, and hepatobiliary disease and pathophysiology. Am J Physiol Gastrointest Liver Physiol 2015, 308: G459-G471

58. Grubb BR, Gabriel SE: Intestinal physiology and pathology in genetargeted mouse models of cystic fibrosis. Am J Physiol 1997, 273: G258-G266

59. Gibson-Corley KN, Meyerholz DK, Engelhardt JF: Pancreatic pathophysiology in cystic fibrosis. J Pathol 2016, 238:311-320

60. Durie PR, Kent G, Phillips MJ, Ackerley CA: Characteristic multiorgan pathology of cystic fibrosis in a long-living cystic fibrosis transmembrane regulator knockout murine model. Am J Pathol 2004, 164:1481-1493 
61. Colledge WH, Abella BS, Southern KW, Ratcliff R, Jiang C, Cheng SH, MacVinish LJ, Anderson JR, Cuthbert AW, Evans MJ: Generation and characterization of a delta F508 cystic fibrosis mouse model. Nat Genet 1995, 10:445-452

62. Kerem B, Rommens JM, Buchanan JA, Markiewicz D, Cox TK, Chakravarti A, Buchwald M, Tsui LC: Identification of the cystic fibrosis gene: genetic analysis. Science 1989, 245:1073-1080

63. Kaplan E, Shwachman H, Perlmutter AD, Rule A, Khaw KT, Holsclaw DS: Reproductive failure in males with cystic fibrosis. N Engl J Med 1968, 279:65-69
64. van der Ven K, Messer L, van der Ven H, Jeyendran RS, Ober C: Cystic fibrosis mutation screening in healthy men with reduced sperm quality. Hum Reprod 1996, 11:513-517

65. Mak V, Zielenski J, Tsui L-C, Durie P, Zini A, Martin S, Longley TB, Jarvi KA: Cystic fibrosis gene mutations and infertile men with primary testicular failure. Hum Reprod 2000, 15: 436-439

66. Chen H, Ruan YC, Xu WM, Chen J, Chan HC: Regulation of male fertility by CFTR and implications in male infertility. Hum Reprod Update 2012, 18:703-713 